\title{
THE GROUND SHIFTING BENEATH US: COLLECTIVE MEMORY OF NEW ZEALAND'S NEOLIBERAL REVOLUTION
}

\author{
BY \\ BRENT JOHN NEILSON
}

\begin{abstract}
A thesis
Submitted to the Victoria University of Wellington in fulfilment of the requirements for the degree of Master of Arts

Victoria University of Wellington

2016
\end{abstract}


The ground was shifting on you, without you even really understanding or knowing it. The kind of way society was structured was shifting, without you really understanding that that was what was happening.

('James', community and voluntary representative). 


\begin{abstract}
This paper explores the collective memory of the neoliberalisation of New Zealand and drastic structural adjustments beginning in 1984 with the election of New Zealand's Fourth Labour government. Through a cultural sociological analysis of narrative, collected through interviews with both community and voluntary and trade union representatives, use of a cultural sociological understanding of thick description and maximal interpretation reveals how seemingly personal accounts and evaluations take on collective significance. In tracing a path from a collective need for change in New Zealand, to a realisation of the impact of structural adjustment and the collapse of New Zealand's Labour tradition, this research concludes that the collective memory of this time in New Zealand's recent history is an ongoing and culturally complex negotiation of collective meaning-making and interpretation. Through an understanding of the collective memory of those who were, and continue to be deeply affected by this period in history, we can begin to understand both the collective impact of neoliberalisation, and the ongoing repair-work needed in New Zealand's Labour Party, and the Left more broadly.
\end{abstract}




\section{Acknowledgements}

I would like to thank all participants who took part in this research for their openness in speaking with me, and willingness to take time out of their personal and professional lives in providing a voice for my work. This research would not have been possible without your support. What struck me through-out our conversations was the participants' absolute dedication to striving for a fair and socially-just society in advocating for workers, families and communities across New Zealand. Through my research, I hope I am able to, in some way, return the favour, by expressing some of the deeply engrained memories, emotions and ongoing concerns related to this period in New Zealand's history.

To my supervisors, Chamsy-el Ojeili and Ben Snyder, thank you for your guidance and support over the course of this study. Life is good under the supervision of two walking sociological encyclopaedias.

To Jean Sergent, Hun Lee, Blake Cambourn, Deborah Laurs, Sandra Grey, Charles Sedgwick the ninth floor and all my beautiful friends and family, thank you. 


\section{Contents}

\section{Introduction 1}

$1 \quad$ Literature Review 5

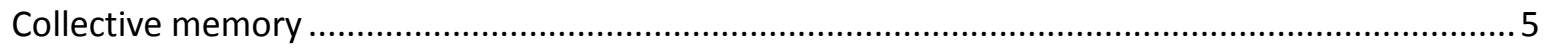

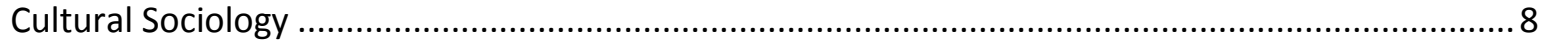

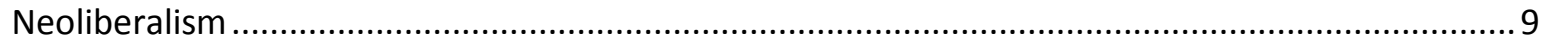

2 Theoretical orientation and methodology considerations 12

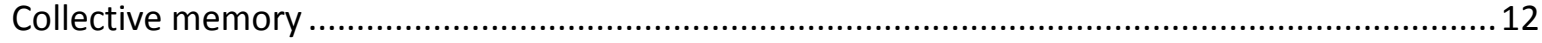

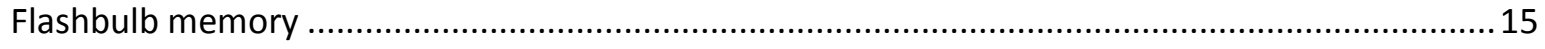

Cultural sociology

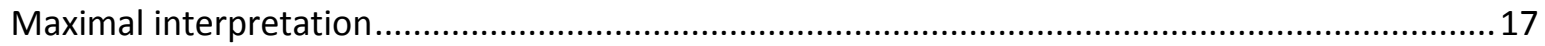

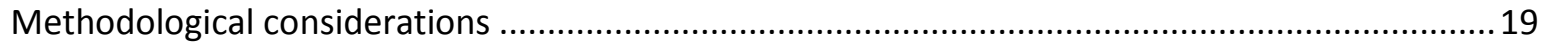

3 Exposition 22

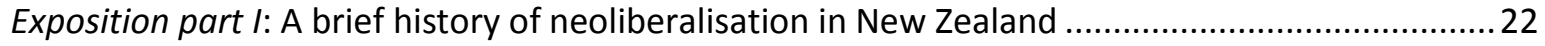

Exposition part II: The organisational and ideological framing of memory......................................2 24

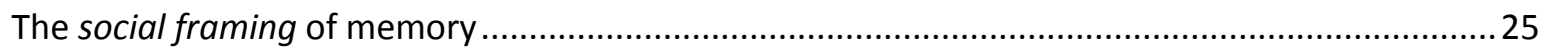

Mnemonic communities and the mnemonic framing of memory .................................................2

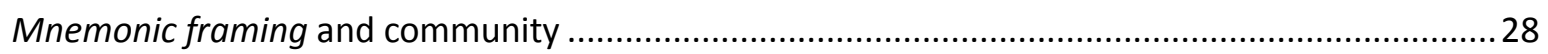

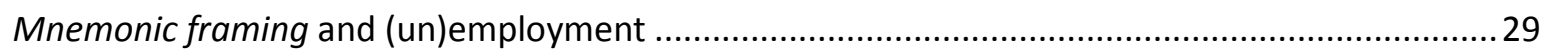

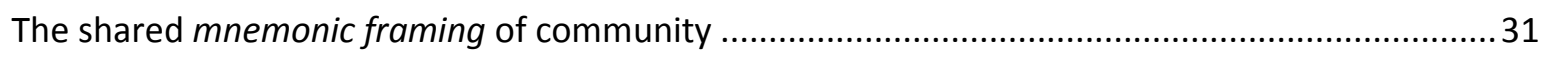

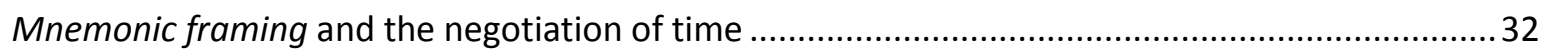

\section{$4 \quad$ Rising action: Historical Density and Social Change in New} Zealand 35

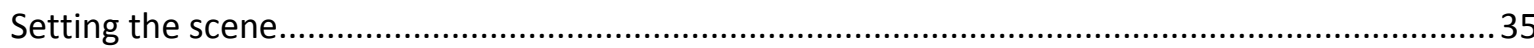

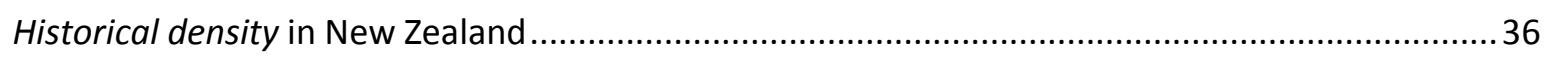

The 1981 Springbok tour of New Zealand and a new political consciousness .................................. 39

The 1981 Springbok tour as cultural disorientation .......................................................................... 43

\section{$5 \quad$ Rising action/Climax: Establishment-New Zealand and the rise of the Fourth Labour Government 45}

The New Zealand-Establishment 
The sacred and profane in New Zealand's social and political discourse...... . .49

Cultural codes and a grand-narrative under siege........................................................................ 51

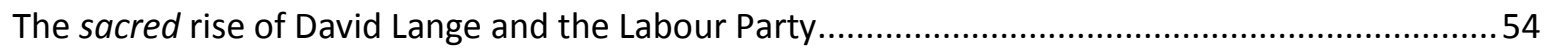

Flashbulb memories and the process of meaning-making ..........................................................5

\section{Climax/falling action: The Realisation of Rogernmomics 61}

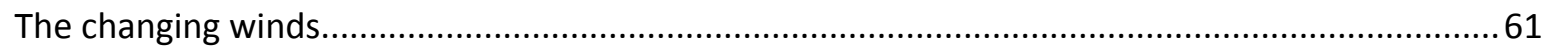

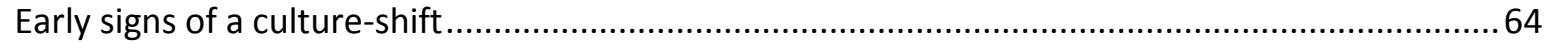

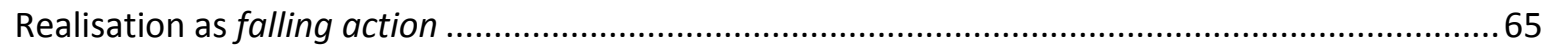

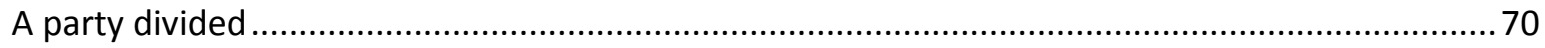

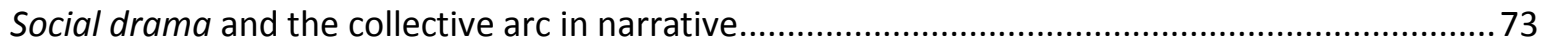

7 Resolution/denouement: Social schism and partial reintegration of breach in New Zealand's Labour tradition 75

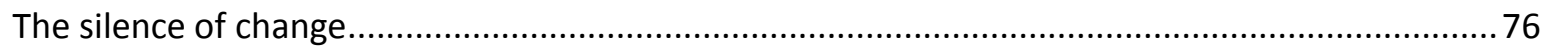

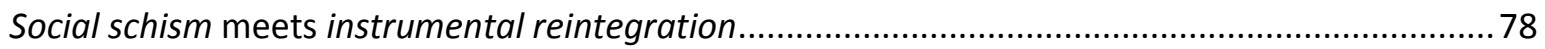

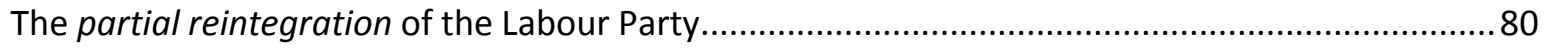

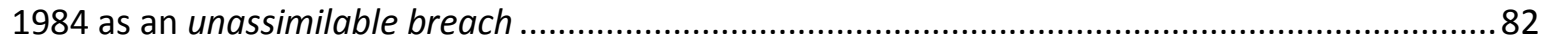

$8 \quad$ Concluding comments 85

Bibliography 88 


\section{Introduction}

Since the 1980s there has been a significant and widespread trend towards neoliberalism globally. Beginning in 1984 with structural adjustments at first implemented by New Zealand's Fourth Labour government, the neoliberalisation of New Zealand remains a hotly contested area of inquiry. Over thirty years have passed since the application of pure neoliberal economic theory in New Zealand, and what would later be coined 'Rogernomics'. The past three decades have seen a number of social, political, economic and cultural developments within New Zealand directly related to this ongoing process of neoliberalisation. Critiques of this economic theory abound in academia, and increasingly in the public arena. Thirty years on, and with a growing understanding of the impact of structural reform on a number of levels, the following research traces a narrative of collective understanding of this period in New Zealand's history through a cultural sociological analysis of the collective memory of two groups integral to civil society in New Zealand: trade union and community and voluntary organisations.

The Labour Government of 1984-1990 was responsible for the creation and application of a dramatic shift in the shape and form of New Zealand society. Viewed as a departure from both a long history of socially progressive policies in New Zealand, and a retreat from the Labour Party's traditional stance on social and economic matters, this shift saw the country transition from the Keynesian, social democratic economy of the three decades following the Second World War, to the neoliberal economy it is today. There are many changes associated with this shift. The Keynesian Welfare State provided an emphasis on high employment, while maintaining a commitment to social democracy through an active state. The neoliberal reforms of the 1984-1990 Labour Government, with its new focus on the 'market' and the promotion of individual self-interest, saw thousands unemployed, and opened the door to the welfare cuts implemented by the 1990 National Government, affecting thousands who were reliant on the state for support.

That there was sudden and significant social transformation during and resulting from this period in New Zealand's history is clear. Few democratic countries experienced the impact of neoliberalism to the extent and speed New Zealand did following 1984. Owing to the speed and scale of reform, 1984 is itself collectively understood as heralding in a period of significant social, cultural, economic and political change. Neoliberal reform is widely 
understood as responsible for the rise in unemployment and welfare cuts from 1984 through the 1990s, and for the transformation of New Zealand society more generally in ways that can be understood as a departure from a history of relative egalitarianism and social support.

Peter Coleman attributes the origins of the American Welfare state to New Zealand's early commitment to socially progressive ideals. Coleman writes,

'the world paid attention when New Zealand gave women the vote and the aged pensions; when it broke up large estates, settled small farmers on the land, lent them cheap money to develop their properties, supplied them with free agricultural services, and subsidised their transportation costs to encourage rural development and market access; when it put the state into the commercial banking, mortgage lending, fire and accident insurance, housing and coal-mining and distribution businesses; when it gave employers the choice between providing decent working conditions or going out of operation; when it imposed a progressive tax on income and land; and when it substituted compulsory arbitration for strikes and lockouts' (1982: 373).

This memory of New Zealand as the 'social and economic laboratory of the world' (Coleman, 1982: 373) has since been displaced by what Jane Kelsey refers to as 'The New Zealand Experiment': a new social and economic laboratory committed to the neoliberal agenda.

New Zealand now places poorly in a host of globally tested social indicators. Income inequality began to take its current form in the United States and the United Kingdom in the late 1970s and early 1980s, while in New Zealand, inequality began to worsen from the mid1980s, with inequality rapidly expanding over the next ten years. Brian Easton, a longstanding critic of neo-liberalism, found that personal income was relatively stable in New Zealand between 1926 and the 1950s and that equality improved through to the mid-1980s (2013). This earlier period of stability following a post-World War II economic boom saw a 'golden age' of prosperity in New Zealand, preceding the beginning of an economic decline in the 1970s, with broad policy responses of first, protectionism, under then Prime Minister Robert Muldoon, and later 'Rogernomics' under Prime Minister David Lange and the Fourth Labour government.

Neo-liberalism between the mid-1980s and mid-1990s saw economic measures put into action that affected New Zealand's traditional, subsidised industries. Coupled with income tax cuts and the introduction of GST (Goods and Services tax), these measures hit the poor 
and not the rich. Matters were only made worse in the early 1990s, as then Minister of Finance Ruth Richardson cut state spending on welfare, resulting in more pronounced inequality. Mimicking global statistics, a New Zealand family in the top ten percent of earners, now has nine times the income of a family in the bottom ten percent (OECD, 2011). The top one percent own sixteen per cent of New Zealand's wealth, while the lower fifty percent has just over five per cent (Rashbrook, 2013). According to an OECD report, the gap between New Zealand's rich and poor has widened more than any other developed country during the past twenty years (OECD, 2008). Of the neoliberal structural adjustments beginning in 1984, O’Brien and Wilkes write,

'It is a tragedy for New Zealand society because of how it transformed the way in which we think of ourselves as a nation and of our relationships with one another. It is a tragedy because of the way in which it failed to take an opportunity to transform New Zealand and build on our history. It is a tragedy because of the way in which the changes flew in the face of both the country's history and the origins of the Labour Party. It is a tragedy because of the ways in which large numbers of New Zealanders were shunted into the sidings and left while the rest of the society travelled past' (1993: 7-8).

The Ground Shifting Beneath Us: Collective Memory of New Zealand's Neoliberal Revolution explores the collective memory of the neoliberalisation of New Zealand and drastic structural adjustments beginning in 1984 with the election of New Zealand's Fourth Labour government. A cultural sociological analysis of narrative, collected through interviews with both community and voluntary and trade union representatives, adopting a cultural sociological understanding of thick description and maximal interpretation reveals how seemingly personal accounts and evaluations take on collective significance. In tracing a path from a collective need for change in New Zealand, to a realisation of the impact of structural adjustment and the collapse of New Zealand's Labour tradition, this research concludes that the collective memory of this time in New Zealand's recent history is an ongoing and culturally complex negotiation of collective meaning-making and interpretation. Through an understanding of the collective memory of those who were, and continue to be deeply affected by this period in history, we can begin to understand the ongoing repair-work underway in New Zealand's Labour Party, and the Left more broadly.

After establishing relevant literature (Chapter 1), and theoretical orientation and methodological considerations (Chapter 2), this study follows a collective arc of narrative presented by interviewees participating in this research. In doing so, the collective memory of 
participants is shown as following a narrative path from exposition (Chapter 3), to resolution (Chapter 7) in the acknowledgement of social schism and partial reintegration with regard to New Zealand's Labour tradition.

While a quantitative analysis of statistics can, among other things, indicate the impact of economic reform on, for example, employment and the numbers affected by welfare cuts, perhaps more difficult to grasp are those 'tragic' aspects mentioned above - those sudden and irreversible changes - to the social, cultural, political and economic fabric of New Zealand society. For this, a qualitative approach must be utilised, one which attempts to find meaning from past events, and which is able to situate that meaning in its present context.

Theoretically, this study borrows from both social memory and cultural sociological studies in the analysis of qualitative data in the form of interview narratives. In treating the body of narrative elicited through interviews with ten participants as 'text', this research illustrates how collective memory can be understood as an intersubjective process of representation and interpretation. 


\section{$1 \quad$ Literature Review}

\section{Collective memory}

Interest in collective memory in the last 35 years has been significantly influenced by the work of Maurice Halbwachs, who coined the term memoire collective in his 1925 work Les Cadres Sociaux de la Memoire (The Social Frameworks of Memory) (1952). Halbwachs' most important contribution to the field of sociology came in his work La Mémoire Collective (The Collective Memory) (1992) in which he puts forward the thesis that groups hold a 'collective memory' and that this memory is dependent upon the framework within which the group is positioned in society. A focus on these social frameworks has led to studies exploring the memories formed in work settings (Orr, 1990; Bodnar, 1989), professional groups (Zelizer, 1992, 1993) and politics (Schudson, 1992). Later distinctions have been made, carrying on from the work of Halbwachs, between 'collected memory', or the aggregated memories of group members (Schuman and Scott,1989; Schuman and Rieger, 1992; Schuman and Corning, 1999; Schuman et al, 1997; essays in Pennebaker et al, 1997), and genuinely collectivist approaches (Schwartz, 1991, 1996; Shils, 1981; Zerubavel, 1996; Olick and Levy, 1997, 1999), highlighting the fact that 'social memory studies' (Olick \& Robbins, 1998) is both 'universal and particular' (Zelizer, 1995).

It is generally agreed two theoretical approaches have organised studies of collective memory. Approaches are differentiated by a focus on the past as a social construction which shapes the needs of the present (Schwartz, 1982, 1990; Maines et al., 1983; Lowenthal, 1985; Schuman \& Scott, 1989; Rousso, 1991) and those which focus on the enduring power of tradition to shape the present (Shils, 1981; Hobsbawm \& Ranger, 1983). A more complex view of the relation between the past and present as shaping collective memory, however, has collective memory understood as an active, dynamic process shifting through time (Olick, 2006; Schudson, 1992; Schwartz, 1991; Trouillot, 1995; Y. Zerubavel, 1994).

Jeffrey K. Olick and Joyce Robbins (1998) construct a tradition of 'social memory studies' by examining the development of the field, the definitional disputes, outlining a historical approach to social memory, and reviewing the sociological theories related to social memory dynamics. The authors refer to social memory studies as a 'nonparadigmatic, transdisciplinary, centreless exercise' (1998: 105), yet with recurring themes across different disciplinary areas. Olick and Robbins conclude by suggesting future directions for the study 
of social memory, including the sociological study of identity, the move to a more 'processual' or 'narrative' approach to social processes so as to not reify process in temporality, and finally the incorporation of social memory into macrosociological theories.

Studies involving collective identity and memory (for Germany see Maier, 1988; US see Kamnen, 1991; 1992) point to the increasing array of symbolic forms and practices which nations adopt and implement in the construction and continuation of a sense of collective self over time. Hobsbawm and Ranger (1983) argue that traditions are invented and maintained for the continuation of specific versions of nationhood. Published over the years 1984-1992, Les Lieux de memoire, directed by Pierre Nora, worked to identify the places and objects which capture and embody the national memory of France, and therefore French identity. The ambitious project worked to not only create a national inventory of these lieux, understood as thematic places of collective memory, but to also expose the propagandistic uses to which such places, and attached memories, can be utilised. The history of memory Nora uncovers is created through both imagined representations and more concrete historical realities that are attached to symbolic sites and which form French social and cultural identity. Nora reminds us of the distinction between memory and history, with the former understood 'in its "sacred context" as the variety of forms through which cultural communities imagine themselves in diverse representational modes" (Nora: IX), as opposed to history's study of evidence-based empirical reality.

Arthur Neal in National Trauma and Collective Memory (1998) examines the major traumas collectively experienced by the American people during the twentieth century. Through the development and analysis of narratives, Neal surveys the collective emotion that emerged following traumatic events ranging from the Japanese attack on Pearl Harbour, to the Watergate affair and subsequent resignation of Richard Nixon. In his treatment of the Great Depression as a major American trauma, Neal notes contributing factors leading to this economic trauma: that all major segments of society were affected, but also that the severity of the depression was experienced unevenly amongst different communities and subgroups. Neal also traces shifts in collective and individual emotion, from, for example, 'greed and economic euphoria', to fear (p. 42), as 'the American dream had turned into a nightmare' (p. 43). The chapter goes on to relate the American values of individualism and consumerism as being counterproductive during the Great Depression, and notes how the general belief in America as the 'land of opportunity' was seriously questioned. 
Katherine S. Newman writes in Declining Fortunes (1993) that in the decades that followed the Great Depression, Americans once again began to believe in the founding American myths of prosperity and opportunity. This prosperity was assumed as a birth-right of American citizens, with each generation expecting to surpass the living standards of their parents. However the economic realities of the 1980s and 1990s, Newman writes, have put an end to such expectations, leaving many doubtful, angry and fearful of what the future may bring. Based upon 150 interviews with Americans from a single, yet typical suburban community, Newman examines the often bitter conflict between generations and subgroups as they grapple with the social, economic and political reality of downward mobility, resentment, and a new America.

In Collective Memory of Political Events, a collection of social psychological perspectives edited by Pennebaker et al. (1997), the authors look first at the 'life' of collective memories, or the creation and maintenance of collective memories over time. Next, the social and emotional processes of collective memories are examined, revealing the manner in which broad collective events incite strong emotional reactions from the group. Finally, the authors explore the construction, distortion and forgetting of collective experiences, through a process of construction, reconstruction and 'forgetting', or the avoidance of the past.

While the cited works on collective memory address the construction of both 'historic' and 'autobiographical' memory (Halbwachs, 1992) and treat periods of national crisis or trauma in differing levels of severity, few studies have engaged directly with members of the public in giving this collective memory of economic events and social change voice beyond broad statements and taken-for-granted assumptions of significant societal change. Such assumptions are not unfounded. Collective memory literature on social and economically significant events largely focus on periods of historic national trauma, change, or contention which have been continually represented and therefore 'remembered' and reconstructed, both in terms of their severity and cultural impact. This research will instead look at the collective memory of an economic 'event'; the structural adjustments which began the neoliberalisation of New Zealand, which is not often articulated, or 'remembered' outside of academia. 


\section{Cultural Sociology}

The cultural turn has had a profound impact on the social sciences, and over the last 25 years, the 'new American cultural sociology' has emerged as a significantly influential movement in itself, with the sociological theorist Jeffrey Alexander at the centre of this development (see Alexander \& Smith, 2003; Alexander et. al 2004; Sztompka, 2000; Thompson, 2013; Taylor Woods \& Debs, 2013).

Cultural sociology offers a lens through which the interpretation of collective meaning can be understood. Through this lens, how a collective interprets and comes to understand social issues and processes, results from the social construction of cultural fact. In this sense, social issues are understood as the result of a process of representation and interpretation. 'Cultural trauma', a theory born from Alexander's (2004) cultural sociology, looks to explain culturally devastating or 'traumatic' events as being constructed by a long process of narration and the signification of collective representations. As cultural trauma is an ongoing process of social construction and reconstruction, implicit in the cultural trauma theory is the acknowledgment of 'collective memory'.

Work on cultural trauma has typically focused on grand historic studies and instances of great human suffering (for work on the Holocaust, see Alexander, 2003; Yair, 2014; Giesen, 2004; the attacks of September 11, 2001, see Smelser, 2004; Slavery see Ayerman, 2002;

Fukushima disaster, see Dinitto, 2014). Spillman (2005) argues that while the dramatic serves as useful in demonstrating important incidences of cultural trauma, perhaps it would be the application of this theory to lesser events that would truly test its worth. Debs (2004) looks at the power of objects and the trauma of loss associated with iconic buildings and artefacts. The Hillsborough tragedy of 1989, while involving the loss of many lives, serves as an example of a recent, localised event which has been treated academically as culturally traumatic (Hughson \& Spaaij, 2011). Such studies need not focus on life and death. Debs (2004) looks at the power of objects and the trauma of loss associated with iconic buildings and artefacts. Piotr Sztompka (2003) employs a theory of cultural trauma in his treatment of drastic social change experienced by post-communist societies, while Toppen and De Kruijf (2014) examine 'socio-cultural dynamics of economic downfall' and implement the work of Sztompka (2000) in assessing Iceland's economic meltdown of 2008 as a 'traumatising change that triggered a process of (national) transformation' (Toppen \& De Kruijf, 2004: 377). 
A core relation identified by cultural sociologists (Alexander, 1998; Alexander et al 2003; Smith, 1982; 1991) and collective memory theorists alike (Schwartz, 1982; 1991; WagnerPacifici \& Schwartz, 1991) is that between socially consequential events and cultural codes. It is here, at the interstices of code and event, trauma and continuity, culture and the economic, the grand and the mundane, that this research sets forth through an exploration of the collective memory of the impact of drastic social, political, cultural and economic change in New Zealand following the neoliberal market reforms of 1984.

\section{Neoliberalism}

Neoliberalism can be understood broadly as both an approach to government, and a defining political movement of the last 40 years. David Harvey writes neoliberalism is,

'in the first instance a theory of political and economic practices that proposes that human wellbeing can best be advanced by liberating individual and entrepreneurial freedoms and skills within an institutional framework characterised by strong property rights, free markets, and free trade. The role of the state is to create and preserve an institutional framework appropriate to such practices...' (Harvey, 2005: 2).

Davies (2014) provides a bibliographic review of texts which recognise the complexity of neoliberalism. Davies cites the 'crisis of Keynesian macroeconomics' in the early 1970s as setting the scene for a widespread paradigmatic shift which initially began in the United States and United Kingdom, but was soon exported internationally. Since the 1970s, the neoliberal doctrine, grounded in the assumption that private companies, individuals and freemarket principles can best foster economic growth and the provision of social welfare, has shaped policies at international, national and local levels. The term 'neoliberalism' is therefore often used pejoratively to describe the perceived threat of global capitalism, consumerism and a disdain for the dismantling of the welfare state (Bourdieu 1998; Chomsky 1999; Touraine 2001; Saad-Filho and Johnston 2005; Plehwe et al. 2006). The widespread use of the term 'neoliberalism' has therefore led some to address its ambiguity and tighten existing definitions (Dean, 20123; Flew, 2014).

Recently there has been an increase in academic work highlighting and evaluating the upsurge in social and economic inequality in developed, western countries thought to be a direct result of the neoliberal turn. These works cover many aspects of this issue, including the extent of the increase in social and economic disparity (OECD, 2011; Perry, 2013), its 
possible causes (Autor, Katz \& Kearney, 2006; Easton, 2013; OECD, 2008) and the various consequences of this increase. Studies of these consequences have focused on the political (Edwards, 2008; Edwards, 2010; OECD, 2011; Bartels, 2008), the economic (Ongley, 2013; Persson \& Tabellini, 1994) and the social (Wilkinson, 1996; Jencks, 2002; Rothstein \& Uslaner, 2005). Related to work focusing on the social consequences, are those studies which focus on public perception and attitudes toward the issue of rising social and economic inequality (Humpage, 2008; Bamfield \& Horton, 2009; Jost \& Major, 2001; Bartels, 2005; Centre for Labour and Social Studies, 2013; Lelkes, 2009; Taylor-Gooby, 2013 ).

Academic literature on neoliberalism in New Zealand cite the economic, political, social and cultural impact of economic reforms beginning in 1984. Boston and Eichbaum (2014) point out that few, if any democratic nations experienced neoliberal reforms to the scale and speed experienced in New Zealand, and note that while some objectives of the economic reforms have been met, the 'neoliberal revolution' has also resulted in increased income inequality, poverty and an increase in the Gini coefficient for New Zealand which sees it being among the highest in the OECD for over 30 years. Jane Kelsey in The New Zealand Experiment (1995) examines the rise of neoliberal economic theory, the attempts made to embed this 'economic fundamentalism' in New Zealand following its initial application in 1984 and the social, democratic, cultural and economic effects, or 'deficits' of neoliberal reform in New Zealand. Following on from Kelsey's study, Humphries (1996) asks how it was that New Zealand, a society which prided itself on an ethos of collective responsibility for social wellbeing, allowed economic reformation that seemed to fly in the face of the nation's historic commitments. Humphries argues neoliberal reformation was predicated on a discourse of collective responsibility for economic results and the prediction of increased wellbeing in the future. Later, Ongley (2013), examined work-related inequalities in neoliberal New Zealand and notes radical economic reforms have led to significant shifts in New Zealand's class structure, while Humpage (2014) provides a longitudinal analysis of public attitudes to social policy since the 1980s and asks whether neoliberal policies have radically changed public beliefs about the idea of social citizenship in New Zealand.

This research combines the political, economic, social and cultural implications of neoliberal reform in New Zealand by uniting collective memory theory, and a cultural sociological analysis of the collective narratives of mnemonic communities. For the purpose of this study, neoliberalisation is understood as the ongoing process of neoliberal reformation in New Zealand. Structural adjustment and structural reform are used interchangeably to denote 
neoliberal policies introduced in New Zealand by the Fourth Labour government (1984-1990) and continued by the Fourth National government (1990-1999). Rogernomics, in the tradition of Reaganomics (US) and Thatchernomics (UK) denotes the New Zealand-specific experience of neoliberal economic policies introduced by the Fourth Labour government's Minister of Finance (1984-1988) Roger Douglas. 


\section{Theoretical orientation and methodology considerations}

There has been a considerable volume of academic works within Aotearoa New Zealand covering the social, political, economic and cultural impact of structural adjustment and the kind of economic fundamentalism indicative of neoliberalism which gained considerable pace in New Zealand in 1984. Much of this work pays particular attention to the increased unemployment experienced during this period, welfare cuts and accompanying social transformation. This transformation can be understood as an apparent shift in values alongside more material transformation of a collective coming to grips with sudden and drastic social and economic change.

While a quantitative analysis of statistics can, among other things, indicate the impact of economic reform on, for example, employment and the numbers effected by welfare cuts, perhaps more difficult to grasp are the 'tragic' aspects associated with; those sudden and irreversible changes to the social, cultural, political and economic fabric of New Zealand society. For this, a qualitative approach must be utilised; one which attempts to find meaning from past events, and which is able to situate that meaning in its present context.

History books teach us much about this period in history, while largely excluding the lived experience of those who were there. Through a narrative analysis of interview data elicited from community and voluntary, and trade union representatives, respectively; stock can be taken of this period of radical change in New Zealand's history. Through an understanding of the deeply entrenched meaning-making found within each groups' collective memory, and the collective arc of narrative created in interpreting, explaining and evaluating this period, we can begin to better understanding the deeply felt and ongoing impact of neoliberalisation in New Zealand.

\section{Collective memory}

The collective memory of a given mnemonic community is not simply the sum total of a group of individual's personal recollections of the past. A collective memory, as opposed to a collected or aggregated memory, must instead integrate personal pasts and individual interpretations into a shared interpretation of the past. Therefore, while individual accounts presented in this study take the form of personal narrative elicited through interviews, with 
idiosyncratic material and interpretive details, the broader work of interpreting and presenting significance in the form of narrative, framing and the binary building blocks of meaningmaking take on a shared, collective form which transcends the individual account.

In the early memory work of Maurice Halbwachs, memory is a matter of how minds work together; not simply the dynamics of minds in constant metaphorical and literal conversation, but of how the minds' operations are structured by certain group-specific social arrangements. Halbwachs writes, 'It is in society that people normally acquire their memories. It is also in society that they recall, recognise and localise their memories' (1992: 32). According to Halbwachs, it is therefore impossible for the individual to recall events or emotions outside the context of their group. These group contexts are what Halbwachs famously referred to as 'Les cadres sociaux de La memoire', or the 'social frameworks of memory'. It is within these social frameworks, and with the social and cultural materials they provide - through collective narratives, symbols and systems of meaning - that memory takes place.

The social organisation created by memory frameworks give a persistent, yet malleable structure in which memories reside. Within this understanding of memory, even the most subjective of memories, those memories laden with the most personal meaning and emotion for the individual, are constructed within the framework of the multiple mnemonic communities to which the individual belongs. Symbols and representations, including narrative as a representation of the past, act as cultural tools utilised in the construction, deconstruction, and reconstruction of meaningful events. Memory, far from being static, is therefore in a constant state of flux. As lesser memories slip from the group consciousness, memories of greater significance are rehearsed and reinforced within the group. This process situates memory firmly in the present, even as it inherently reflects on the past, and it is therefore susceptible to the needs, assumptions and concerns of not only the present, but an imagined future.

It is true that while collective memory survives and thrives through these frameworks, it is the individual his or herself, as a group member, that remembers in the physiological sense. While memories are supported by a given community, individuals experience memory as being a highly personal, subjective experience, and therefore may experience the memory of an event with greater or less intensity, with perhaps emphasis placed on one matter or other to varying degrees. Similarly, each individual's personal account of an event may take on 
autobiographical shape if the individual were present at the moment or during the time of the event itself, and therefore may differ from other group members along generational or autobiographical lines. Halbwachs himself suggests perhaps 'each memory is a view point on the collective memory, that this viewpoint changes as my position changes, [and] that this position itself changes as my relationships to other milieus change' (1992: 142). However, this subjectivity is still reliant on the social frameworks provided by the group, with the individual's experience of memory supported by their changing relationships to and within other groups. An example of this can be found in the overlapping of the social frameworks of memory created by the individual's membership to a given nation, ethnicity, political inclination, organisation, and family and the dynamic of these overlapping frameworks of memory and understanding.

Broadly speaking, there are two theoretical approaches illustrative of 21 st century studies in collective memory. Schwartz $(1991 ; 2000)$ distinguishes between 'presentist' and 'traditionalist' models. Presentist models see the past as an entirely flexible construct, as a prisoner to the wants, needs and concerns of the present. Memory in this sense is open to active manipulation. However, a more sympathetic view of presentist models sees memory as an ongoing social construction, constantly shaped and reimagined through interactions with the group. Traditionalist models, on the other hand, view memory as being in a constant state of maintenance, akin to traditions of heritage and national identity which are maintained over time. In the traditionalist model of collective memory, the theoretical focus falls on continuities of our perception to the past, while the presentist approach focuses on discontinuities (Schwartz, 1991). In his promotion of a "non-reificatory approach to collective memory', Jeffrey Olick (2006: 13) helpfully asserts, 'neither of these views, however, is a particularly insightful way to understand the complexities of remembering, which is always a fluid negotiation between the desires of the present and the legacies of the past'. In agreement with Olick, this research takes a pragmatic, non-reificatory approach to social memory studies and collective memory, by understanding the process of remembering as 'a fluid negotiation between the desires of the present and the legacies of the past' (2006: 13). Collective memory is therefore understood here as an active process of sense-making through time. 


\section{Flashbulb memory}

A common feature of the narratives of participants involved in this study was the infrequent yet significantly meaningful use of a more in-depth, descriptive, highly personal and emotional form of storytelling indicative of 'flashbulb memory'. Roger Brown and James Kulik coined the term flashbulb memory to describe 'a vivid recall of the circumstances in which one learned of some important event' (1977: 78). The authors cite high levels of surprise, consequentiality and emotional arousal as determinants of this form of memory (1977: 73). Psychologist Michell L. Roehm writes,

'Flashbulb memory is a potent type of autobiographical memory that can be formed after an extraordinary event takes place. In comparison with other autobiographical memories, flashbulb memories are considerably more vivid, include more contextual detail, and are more confidently held' (Roehm, 2015: 1).

Of particular interest is the role of emotion in flashbulb memories. Christianson (1992), Gold (1992), and Reisberg and Heuer (1992) all argued that emotion's effect on memory can account for most of the flashbulb memory phenomena, leading many to view emotion as a possible 'special mechanism' that explains the retention of these memories, and the flashbulb phenomenon. This study adopts a variation of an understanding of the term 'flashbulb memory' in which highly detailed and emotional events which structurally follow the form of narrativised accounts are determined by more than simply the magnitude or consequentiality of the event which triggers the autobiographical act of remembering, but by the impact of emotion on the individual. This emotional impact creates a mental event of significance which is attributed meaning through group interactions over time. In this way highly personal events can, in a sense, become mythologised within a given mnemonic community, as new information regarding the event in question comes to light, or as the impact on the group itself is evaluated.

\section{Cultural sociology}

The analysis of collective memory in the form of narrative elicited through interviews borrows from a cultural sociology which uses 'structural hermeneutics' (Alexander \& Smith, 2003) and an interpretation of thick description to render meaning from social 'text'. Understanding meaning as text allows for the incorporation of literary theory and method in the analysis of social phenomena. Jeffrey Olick writes, 
'Collective memory is something - or rather many things - we do, not something - or many things - we have. We therefore need analytical tools sensitive to its varieties, contradictions and dynamism. How are representations of and activities concerning the past organised socially and culturally? When and why do they change? How can we begin to untangle the diverse processes, products, and practices through which societies confront and represent aspects of their past?' (Olick, 2006: 13).

A cultural sociological reading of collective memory using Alexander and Smith's 'structural hermeneutics' is shown here as indeed providing such tools in the analysis of the collective representations which constitute group memory.

In developing structural hermeneutics, cultural sociology borrows from Geertz (1973) the notion of 'thick description' in the social sciences in reconstructing social actions. Geertz considered description as 'thick' when it is not only thoroughly informed, but culturally placed in context. Thick description in this sense is, therefore, a potent reconstruction of social actions and processes resulting from a circularity of evaluation and description, construction and meaning, rather than merely a comprehensive observation (Alexander, 2008). This research utilises a cultural sociological understanding of 'thick description' beyond a primary concern for a certain level of descriptive detail. Rather, it is the interpretative characteristic of description that can be termed 'thick', as opposed to the kind of detailed account present in ethnographic studies. This study therefore follows Denzin in his assertion that thick description 'involves capturing and representing the meanings a particular action or sequence of actions has for the individual in question' (2001: 10). Similarly, Holliday (2007: 75) writes,

'What makes the thick description of social phenomenon possible is not its exhaustiveness of coverage, but the way in which it scans the different facets of the social matrix or culture within which it is found, and comes up with a good analysis'.

Meaning-making as a process undertaken by both the interview participants and researcher is an ongoing dynamic which constantly considers the data elicited against larger, 'historicallyshaped institutional patterns' (Lamonth \& Swidler, 2014: 161). Lamont and Swidler (2014) note that a downside of interviews is their potential to lead us to assert a certain coherence in narrative. They use the example of a life told in retrospect which when told will seem to have an air of inevitability that a life in the present, 'real world' does not. This research celebrates this inevitability as time has allowed whole communities to share and shape their collective narrative of events in their past. 
With meaning central to cultural sociology, structural hermeneutics utilises literary tools traditionally used to examine art and language. From an analytic perspective, this turn toward literary theory, particularly the use of performance and drama, allows the researcher to include emotion in his or her analysis of culture. Emotion becomes central to cultural sociological analysis as it serves to convey and explain the patterns of impact and recognition of performance and symbolism which are at the core of cultural sociological theory. This is best illustrated in the use of binary codes, metaphor, framing and the narratives by way of which these elements are conveyed. These binary codes can be understood as a 'language' located within narrative at both the individual and societal level. At the level of the individual, personal histories are framed within a larger narrative socially shaped by the community of which they are a part.

Jeffrey Alexander argues the 'strong program' he promotes in cultural sociology is committed to and reliant on the autonomy of culture (2003). This analytical autonomy sees culture as an independent variable, severed from social structure; the uncoupling of which allows for a real appreciation of the importance of culture in forming social life (2003). Alexander contends culture is not a 'thing' to be explained by another 'thing', removed from the domain of meaning, but an autonomous dimension of itself. Culture and meaning-making, Alexander argues, should therefore be situated at the centre of sociological understanding and analysed on its own terms. This study acknowledges both the relative autonomy of culture espoused by the strong program in cultural sociology, but also the contingency or dependence of culture assumed by the relatively 'weak programs' of cultural studies and the sociology of culture. While the tools of literary critique and neo-Durkheimian theory are utilised in the structural hermeneutic reading of texts, cultural coding inextricably bound to power and institution is isolated from the narratives of participants for analysis, further lending to a greater cultural understanding of the research material in question.

\section{Maximal interpretation}

In developing an understanding of meaning and significance in the analysis of collective memory, this study moves from a minimal form of interpretation, one which merely establishes social actions in our past, toward a maximal interpretation which situates the interpretation of meaning as being central (Reed, 2008). Isaac Reed defines maximal interpretation as, 
'a type of interpretive manoeuvre, aimed at social life, which is theoretically driven and epistemologically risky, and which claims to know more about human research subjects than they know about themselves. This form of interpretation [Reed argues] is achieved through the productive intersection of the investigators context with that of his or her research subjects, an intersection which is of necessity constituted by a series of interpretations that reach beyond both established theory and gathered fact' (2008: 188).

The meaning-making involved in the interpretation of collective memory through thick description, that is, an interpretation which goes beyond the mere documenting or reporting of aggregated or collected memories, requires by necessity a form of maximal interpretation. Reed continues,

'The Geertzian epistemological point is not only that all explanations are maximal interpretations, but that for a maximal interpretation to be a good interpretation, for it to arrive, indeed, at a deep explanation of a social phenomenon or historical outcome, it must deal in meaning. For it is through the explication of social meaning that we grasp the structured specificities of this or that social context... (Reed, 2008: 197).

Similarly, hermeneutics, in the reading of social memory, is a task undertaken by both researcher and participant, as both look to make sense of the past. Memory involves the constant mental reconstruction of the past. Therefore, as the individual constructs a memory during the interview process, they are both building-on and reconstructing a possible version of any given time or event, and its significance. Freeman (2014) writes,

'Hermeneutics helps us to understand that the value of a certain line of questioning can only be assessed in regard to where it leads or does not lead. Reminding ourselves that the hermeneutic task is to help the topic of our interest say something new, the process needs to be one where we are flexible and able to switch approaches when needed' (Freeman, 2014: 829).

Considering the narrative of each participant as more than simply an autobiography, but rooted deeply in their mnemonic communities moves this method of qualitative analysis away from what might be considered methodological individualism. Collective memory is more than simply the sum of individual memories of any given group, it is an intersubjective and ongoing, collective process of representation and interpretation. While individual accounts can be deeply personal, and subjective in their many idiosyncrasies, an understanding of the social construction of memory allows for generalisation that can find shared meaning far beyond the confines of that offered by the individual alone. The mobilisation of analytic tools used within cultural sociology, and utilised in this study, can 
therefore demonstrate a broad and more meaningful understanding of seemingly subjective views and personal memories.

\section{Methodological considerations}

This research uses an open-ended, pragmatic approach to interviewing, where the aim is to elicit data pertaining to shared representations, cultural ideals and, emotional states and processes of meaning-making; occasionally asking for specific examples when participants offered generalised views, but otherwise keeping the general line of questioning broad, and the resulting narrative largely uninterrupted. As such, the form of open-ended interviewing adopted for this study began, routinely and for each participant, with the opening question:

'What has been your lasting impression of the election of New Zealand's Fourth Labour government and the structural changes which followed?'

Open-ended interviewing allows the practitioner to probe the inherent meaning of what Hochschild (2003) calls 'magnified moments' and what this study identifies as being the result of instances of 'flashbulb memory'; moments which resonate with the individual, are laden with meaning and significance and which can be interpreted through the narrative form they take. This form of interviewing also allows the dialogue to be led by the area of interest itself and a general flow of recollection on the part of the participant, while always being conscious of the dynamic between participant, researcher, and the larger social context in which the interview is taking place.

With human ethics approval granted by Victoria University of Wellington (Ethics Approval: 22273), the narratives collected here are informed from interview material recorded and transcribed from conversations with ten individuals: five community and voluntary representatives, and five trade union representatives. Of the ten participants, a distinction must be made between those who were 'politically active' during the period in question, and those who were not. For the purpose of this study, 'politically active' can be understood as referring to those individuals with formal ties to a major political party. Of the community and voluntary representatives, one individual self-identified as having been formally aligned to the Labour Party at the time of New Zealand's general elections in 1984. Of the trade union representatives, three participants also self-identified as having been formally aligned to the Labour Party during this period. Of the community and voluntary representatives, two 
participants were female, and three male. Of the trade union representatives participating in this research, two were female and three male. Participants ranged in age from between 50 years of age, and 80 years of age. Each interview ran for approximately ninety minutes.

Trade union and community and voluntary represents were selected as communities for analysis for both their historical and ongoing importance in civil society, and for the continued impact both experience as a result of neoliberalisation.

While thick description used in ethnography often seeks to describe in rich detail the participants of the study in question, this research, for ethical reasons, maintains the confidentiality of participants and therefore does not attempt to detail individual attributes or circumstances which may be used to identify any one individual. Accordingly, participants were assigned pseudonyms which appear in this study alongside excerpts of narrative. In keeping with the collective nature of interpretation adopted for this research, excerpts of narrative were chosen to appear in this study that were identified as bearing the most collective significance to participants. The contribution of each participant was invaluable to establishing a collective arc of narrative. Where participants have not been quoted, their voice nonetheless resides in the collective significance of those excerpts chosen to appear in text.

'Thick description', as used in this study, refers to the act of interpretation and the dynamic between researcher and participant in the process of meaning-making. While the personal details and life-histories of participants undoubtedly shape the recollections of each participant, this study focusses on the collective memory of participants, as opposed to the groups' collected memory. Where general personal details of the participant offer context to a given excerpt of narrative, without jeopardising the confidentiality of the individual, they are offered. However, in keeping with the collective nature of this study, the following work adopts a level of generality that lends itself well to collective and social memory studies. The result is a collective narrative which transcends the individual and treats highly personal emotions and experiences as a part of a broader arc of narrative.

In order to analyse interview and archival data, analysis began with individual quotes, topics, themes and other areas of interest. Meaningful relationships were then made between these elements, and developed into structural theories. What is uncovered through this form of analysis is not the truth or validity of a system of meaning, but an interpretation which provides a framework for the development of an understanding of how systems of meaning 
operate, and how this informs a collectivity in their memories, beliefs and values. Barbie Zelizer writes,

'In distancing themselves from personal recall, collective memories help us fabricate, rearrange, or omit details from the past as we thought we knew it. Issues of historical accuracy and authenticity are pushed aside to accommodate other issues, such as those surrounding the establishment of social identity, authority, solidarity and political affiliation' (Zelizer, 1995: 217).

In accordance with this claim, the following research does not look to establish the validity of any claim or aspect of individual memory in terms of its 'truth' or general likelihood. The important issue for a community-specific study of collective memory is not how accurately a recollection fits within established traditionally-historical accounts, or the congruity of individual accounts within the group, but the meaning ascribed to given events and the interpretation of these meanings.

Understood communally, the shared meaning apparent in the collective memory of participants can be understood as following a collective arc of narrative. This arc is defined here as consisting of five sequential phases. First, the exposition introduces key characters and setting. Second, rising action denotes a series of events that complicate matters and create rising suspense and tension in the storyline. Next, the climax sees the point of greatest tension in the narrative and signals a turn to falling action. The falling action phase in the arc of narrative has the unfolding of events in the plot line and precedes resolution, which ends the story and typically resolves problems that are presented over the course of the narrative arc. 


\section{Exposition}

\section{Exposition part I: A brief history of neoliberalisation in New Zealand}

The following exposition represents an approximation of a collective narrative within the social sciences of New Zealand's political history, leading up to, and including, the structural adjustments of 1984. Knowledge of this narrative was evident in the collective historical memory of participants of this study. Expressed here in historical prose, this brief history of neoliberalisation in New Zealand represents the range of historical knowledge presented by participants, and is incorporated here as a crucial work of exposition, in developing an understanding of the period in question.

Over the nineteenth and early twentieth centuries, New Zealand gained a reputation of being the 'social and economic laboratory of the world' (Coleman, 1982: 373), and the 'birth place of the 20th century' (Parsons, 1904: 715). From being the first country in the world to offer Universal Suffrage in 1893 and the introduction of aged pensions in 1898, to the establishment of social housing in 1937, New Zealand was long perceived as a land of social and economic progress. The First Labour Government of 1935-1949 made a wide range of progressive social reforms, a tradition continued by successive government from both sides of the political spectrum.

In 1972, New Zealand elected a social democratic government led by Norman Kirk. This Labour government seemed determined to achieve several long-held goals of the Labour movement in the provision of free medical care, free tertiary education, and extensive social welfare benefits (Quiggin, 1998). The 1950s-1970s were a time of relative prosperity in New Zealand. Incomes were comparatively high and the post-World War II boom saw a growth in spending on housing and education. Major innovations over this period saw the introduction of the Domestic Purposes Benefit in 1973, and ACC (Accident Compensation Corporation) in 1974. However, by 1975, the collapse of the post-war boom, which saw a relative 'golden age' of prosperity in New Zealand, had led to the downfall of Norman Kirk and the Labour government. The government that replaced the Labour Party was led by the conservative and polarising personality of Robert Muldoon and New Zealand's National Party.

The Muldoon era represents one of extreme interventionism, albeit in its conservative and frequently reversed form. In answer to the global economic crisis of the early 1970s, the end to New Zealand's favourable export terms with the United Kingdom following the UKs entry 
into the European Economic Community, and the second oil shock of 1979, Muldoon set about creating an export-led recovery based on new primary processing industries and energy projects Muldoon termed the 'Think Big' programme. It was hoped that these projects would earn international funds and create jobs, but by the early 1980s it was clear these hopes were misplaced. The predicted boom never eventuated and the various projects resulted in international debt. Slow economic growth during this period, while clearly indicating a failure in Muldoon's stimulus projects, also seemed to contrast the seemingly boundless resources the country had its disposal (Quiggin, 1998). Blame quickly turned to Muldoon and the National Party, as this slow growth was understood by many to be a result of the failings of the national economy, rather than part of the wider economic crisis.

The New Zealand Labour party, led by David Lange, won the 1984 election and replaced Muldoon's National government on a platform of traditional social democratic policies. However, backstage, incumbent Finance Minister Roger Douglas had, since 1980 with his book There's got to be a Better Way, been developing a radically new policy agenda, which by the time of the 1984 election was the blueprint for a radical free-market programme. The atmosphere of crisis which resulted from years of stagnant economic growth, coupled with a political system in New Zealand which at the time permitted governments to make drastic changes through high representation in seats of parliament, led to the beginnings of what Brian Easton (1994: 215) calls a 'blitzkrieg' approach to policy reform. This blitzkrieg approach meant the Fourth Labour government was able to implement their policy programme, spearheaded by Roger Douglas, without regard for the concerns of the public, or opposition within the Labour Party itself. The scale of reforms, which led to a programme of deregulation and privatisation, was drastic and more widespread than that experienced within other Western democracies. For a sense of scale of the reforms, Reardon and Gray (2013: 1) list measures taken as including,

'deregulation of financial markets; removal of exchange rate regulations; floating of the NZ dollar; abolition of price controls and interest rate controls; relaxation of overseas borrowing; abolition of import licensing; reduction of trade barriers; abolition of industrial production controls; removal of agricultural subsidies; a general sales tax to move the burden from direct to indirect in taxation; privatisation of state assets, including NZ Steel, Telecom, and the national rail network; restrictions on trade unions; public sector reform, including short term contracts, performance 
management, and private sector consultants in the civil service; and removal of consultative organisations from economic policy-making'.

This drastic programme of economic reform was later referred to as 'Rogernomics', after then Labour Finance Minister and key architect of reforms Roger Douglas, and led to largescale redundancies, increased unemployment and income inequality, and an adverse impact on communities around the country (Kelsey, 1995).

The years 1984-1990, encompassing the Fourth Labour government's two terms in power and the radical structural adjustment of New Zealand's economic system, caused tension within the Party. The New Zealand public also grew increasingly critical of Labour as the impact of continued structural change and a recession in 1987 were felt, leading to the resignation of Lange, a fracturing of the Labour Party, and the 1990 electoral win for Jim Bolger and the Fourth National government.

Following the precedent set by the Fourth Labour government, Jim Bolger's National government continued a programme of extensive cuts in spending. This programme under National became known as 'Ruthanasia', after Finance Minster Ruth Richardson, and saw the reduction of a host of social welfare benefits, and the introduction of fees for both healthcare and tertiary education, further cementing the undoing of New Zealand's socially democratic and progressive status ${ }^{1}$.

\section{Exposition part II: The organisational and ideological framing of memory}

Moving on from part I of the exposition stage in the collective arc in narrative presented by participants is the organisational and ideological framing of memory. Theories of framing generally assert that frames confer perspective on events, issues and people and in doing so, function as a means of making sense of social life and events (Edy, 2006). Social memory studies teaches us that how we frame events, past and present, is socially informed through the 'mnemonic communities' (Zerubavel, 1996) of which we are a part. Similarly, cultural sociology understands organisations, institutions, and therefore mnemonic communities as being shaped by the meaningful ideals and histories they hold central, and which shape their goals and shared social memory. In this way, individuals align their personal, autobiographical memories, and detailed historical memories of an event or time within a

\footnotetext{
${ }^{1}$ For further reading on neoliberal reforms and structural adjustment see: Kelsey (1995); Jesson (1992); Easton (1997) \&; O’Brien and Wilkes (1993).
} 
socially constructed, collective understanding of the past. Traditionally, these mnemonic communities have been imagined in much of the social memory literature to date as consisting of large communities with a shared history and imagined identity, with the nation and ethnicity receiving the majority of attention, while Halbwachs also payed attention to the collective memory inherent in familial relations. More recently, limited interest has turned to organisational memory studies (Booth et al. 2010; Nissley \& Cassey, 2002), which apply the social constructionist perspective of social memory studies to organisations, and in doing so treat organisations as mnemonic communities which create, maintain and reorder memory through shared language, narratives, rituals and symbols. In establishing part II of the exposition stage of the collective arc in narrative as constituting the organisational and ideological framing of memory, we begin to see the ways in which collective memory is framed and therefore shaped by the mnemonic communities of which the individual is a part.

\section{The social framing of memory}

The foundational premise of social memory studies is that our social environment informs what we remember about the past and how we remember it. Zerubavel (1996: 238) writes,

'The first step of a sociology of the past is the realisation that our social environment affects the way we remember the past. Like the present, the past is also part of a social reality that, while far from being absolutely objective, nonetheless transcends our subjectivity and is commonly shared by others as well'.

Much of what we remember as individuals is filtered through a process of interpretation, and the ongoing interpretative work that occurs is continually shaped with reference to the present social environment the individual finds themselves in, whether that be at the family, national, or organisational level. This interpretive work also occurs with reference to events that reach back further in the collective memory of given mnemonic communities, and perhaps even with reference to an imagined future. The mnemonic communities of which we belong serve to frame our memories, and thereby couch our collective hopes and regrets, with respect to the past, present and future, in the ideologies, aims and objectives of the given collectivity. Here, Zerubavel (1996), points to the 'mnemonic lens' through which the past is viewed and interpreted. While narrative-based inquiries into past events are undoubtedly shaped by a given mnemonic lens, in this case one constructed by either the community and voluntary sector, or the trade union movement; the past is also then actively framed by an individual 
with socially constructed and perhaps distorted memories also viewed in a certain light, or to a given ends. This study therefore expands on Zerubavel's conception of the mnemonic lens in suggesting a process of mnemonic framing, which implies the active organisational and ideological construction of memory.

The early founders of sociology understood history as shaped by 'transhistorical progressive laws' (Sewell, 1990: 2). For them, the qualities of history, including both direction and meaning, were a result of causal forces which stretched through time, rather than contingent events which together shape the course of history (Sewell, 1990). Subsequent theories of temporality have challenged this view, including William Sewell's notion of evenemential temporality. In challenging the established transhistorical and progressive view of history, Sewell adopts a position which 'assumes that events are normally "path dependent", that is, that what has happened at an earlier point in time will affect the possible outcome of a sequence of events occurring at a later point in time' (1990: 16). This path dependency means that the timing of events in a collective's shared history critically affects the event's outcome and consequences. Furthermore, the evenemential conception of temporality not only asserts that social relations and historical processes should be considered as path dependent, but that causality is temporally heterogeneous and globally contingent (Sewell, 1990). This understanding of temporal heterogeneity is also evident in social and collective memory studies as the social frameworks of memory undergo constant and complex negotiations with the past, present and future. Sewell continues,

'events bring about historical changes in part by transforming the very cultural categories that shape and constrain human action. Since the causalities that operate in social relations depend at least in part on the contents and relations of cultural categories, events have the power to transform social causality' (1990: 17).

This evenemential understanding of the relationship between causality and social transformation positions periods of significant social disruption, change and mobilisation as crucial in the analysis of and meaning ascribed to subsequent events. The mnemonic framing of collective memory with regard to the relationship between events in the groups' past, and their present needs and circumstances further lends itself to the utility of an evenemential understanding of temporality in collective memory and the ongoing significance of important events in our shared past. 


\section{Mnemonic communities and the mnemonic framing of memory}

Responses to major events in a collective's history are highly varied and dependent on the nature and scale of the event in question. Trauma on a national scale can challenge old narratives, just as periods of great achievement can also. What is true for collective responses of the type created by and within mnemonic communities is the tendency for these responses to become, in a sense, standardised, or even mythologied, in defining the moral boundaries of the group (Neal, 1998). When politicised, these moral boundaries take the form of an ideological framework, as Halbwach's social frameworks of memory become both the architecture for memory maintenance and transference between generations, but also the content. While the content of memory may be similar in essence between groups, the design

- the interpretation and meaning of the event - will be ideologically coloured. In this way, mnemonic communities are largely defined by shared identities arising from the framing of significant events in their history.

Shared suffering or achievement that result from social disruption define the group as not only a mnemonic, but moral community of shared symbols, narratives, rituals and meaning. When such disruption occurs, those shared explanatory features of the group may need to be re-examined or imagined in order to make sense of and address the event in question, if the event, by its negative implications, threatens the cohesion of the group. As often is the case, when the event threatens the collective on ideological grounds, and sense-making has been effectively transmitted and consensus is found within that community, the event itself may become a symbol of a greater threat, concern or adversary; a point to stand against in stark opposition, creating a greater sense of cohesion along ideological lines. Arthur Neal (1998: 31) writes 'Extraordinary events border on the sacred rather than the mundane'. As the event is defined as in conflict with the ideals of the group, a greater binary distance between sacred symbols is established, as the moral/mnemonic community aligns itself against or with some greater meaning attached to the event.

A thematic analysis of interviews with community and voluntary, and trade union representatives indicates two essential ways New Zealand's structural reforms of the 1980s are framed. In the case of the community and voluntary representatives participating, the past is framed with constant reference to the impact on family, while trade union representatives were more inclined to frame their recollections with reference to employment. Where the two focusses of framing meet is in the effect unemployment and changing employment relations 
has on the family and wider community, while a broader understanding of community, and the impact of a weakened sense of community was shown as being crucial to the work of both groups of participants. While this may seem an obvious conclusion to reach, it is nevertheless an important first step in the analysis of narrative which reflects social memory of past events. By acknowledging the mnemonic framing of events and of memory itself, we can begin to understand how and why certain memories may take precedence over others, why some events are remembered and others forgotten - perhaps even actively - and we also begin to understand how and why time is negotiated in the structure of narrative.

\section{Mnemonic framing and community}

Early indication of how New Zealand's structural reform would be framed by participants was often evident in initial recollections of the period following a broad line of questioning which sought to reveal participants' first thoughts on the matter. The recollection of a current community and voluntary representative - a law professional at the time of the Fourth Labour government coming into power - illustrates the initial framing of his memory of this period as being centred on the perceived loss of community the advent of Rogernomics and structural adjustment would herald,

I think back to 1984, this is my memory, the memory of a practicing solicitor, was that our communities were a whole lot closer. Our streets were a whole lot closer. So when I was dealing with clients who were coming in and paying me to buy or sell houses, just a small point, they seemed to be...there was a lot more emotion around someone selling a house in a street, back then. Whereas I know from friends who are lawyers now that it's just a transaction. So that says to me that back in 1984, when you owned a property - this is Wellington that I'm talking about-you were much more likely to be connected with the neighbours in that street of yours, and your children were much more likely to be connected with children in that street than they possibly are today. Today I think property for a whole lot of people, is much more, you know, it's an asset, and basically I think we judge people a lot more in terms of the assets they've got. Back in 1984, I just know that dealing with people in terms of buying and selling, there was a lot more of an emotion about the purchase than I think there is today. So that's my perspective from where I was at the time.

$$
\text { ('John', community and voluntary representative). }
$$

In this account, cultural change is centred on the Fourth Labour government and David Lange's being elected to Prime Minister in 1984, and the subsequent loss of community which was thought by the participant to have been the result of a culture shift in New 
Zealand. While no specific reasoning for this shift is outlined in this piece of narrative, the assertion that prior to this shift 'there was a lot more emotion around selling a house' and that today buying or selling a house is just a 'transaction', is indicative of critiques of neoliberalism which focus on the cultural impact of increasing commercialisation, individualism and a subsequent loss of community. The participant's opening response, and their framing of memory around this loss of community, is undoubtedly informed by their current role as a community and voluntary representative. However this framing also serves as an evaluating feature of narrative, and a constant point of reference to orient both parties involved in the interview, as 'community' is repeatedly referred to throughout the interview in past, present and future tense in establishing and emphasising the notion of loss.

\section{Mnemonic framing and (un)employment}

In terms of increased unemployment and its impact on families and community, community and voluntary representatives recalled the privatisation of state-owned assets in New Zealand as being a major disruptive force of the 1980s, as neoliberal reform pushed for the rationalisation of industry and public services amidst calls for greater efficiency. Again, by framing memory with reference to families and community, participants were able to create a causal link between events of the past, and their organisation's aims and objectives,

One of the big impacts in Oamaru was the restructuring of the railways. I read the stats that the year before New Zealand Railways was privatised there was something like 32000 people working at the railways. Then over the next 12 to 18 months that came down to something like 7000. In a town like Oamaru, that was an awful lot of families. So I had families that had been used to living off one wage, often accommodated in rural houses, suddenly being booted off work, out of the house, and those men had gone from being the income earner, to being nothing. Often that really produced a high level of friction in the home. Men were at home all day, not knowing what to do with themselves and feeling impotent because they were no longer the bread-earner for their family. They had been bought up with the expectation they would be the bread winner for the family, and that was gone. That often led to drink, drugs, which both had another impact on the family income and that kind of developed into this spiral where a lot of the relationships did break up...

The participant continues this historical account with an autobiographical turn as he situates himself, and the collective of which he was a part, within the memory itself, before offering further evaluation of the impact of structural reform on families, 
...(We were) working in that whole area of creating employment and ensuring families had enough food and creating positive things for people to do, rather than locking themselves away in their flat. And what we found was that our families were under real pressure to...the financial implications of our families meant that they were struggling with getting enough food, with paying rent, with paying the power and surviving. And that often led to real friction within those families and so a number of relationships and families broke up over that time, and it was obvious that part of the driver for that was the financial stress those families were under.

('James', community and voluntary representative).

For trade union representatives, this connection between employment and community was often called upon instrumentally to highlight the ongoing struggles of the trade union movement itself. While unemployment and changes made to employment relations were central to the recollections of this group of participants, and were therefore key to the framing of memory, the rise of individualism related to neoliberalism, and the subsequent loss of a sense of community was understood as a shift in values which severely impacted communities across New Zealand, but also the union movement itself. Memory, in this sense, is therefore framed in such a way that it is used instrumentally to highlight ongoing organisational concerns,

I think there were a lot of young people that came into the workforce in 1990-93 that have been effected by it, and who were probably quite disadvantaged by that period, and you know, were very much affected by that individualism. I think people now are very much more aware. I think the under 30s are much more politically aware than that grouping. The union movement lost a whole generation...

('Adam', trade union representative).

It's all based on individualism. I think there was more of a community spirit. Now it's all value: the value of money. Commoditised, I think, and I think there's even less involvement in politics because they've been able to... There's such a mystification of society now, and it really operates in encouraging people to be individual and not stand up for themselves, and not think about life and what the real base of it is.

('Bill', trade union representative).

Repeated use of the term 'individualism' and the implication of an increased focus on economic over social value is here positioned within the trade union mnemonic community as profane and in contrast to the group's sacred ideal of collectivism. This process of profanation is implicit in comparative and evaluative work by the participant as memory of the past is repeatedly applied to the mnemonic community's collective needs and concerns of the present. 


\section{The shared mnemonic framing of community}

Where the framing of memory by both community and voluntary, and trade union mnemonic communities meet is on the wider societal issue of community in New Zealand. While both groups adopted organisation or group-specific framing, with community and voluntary representatives focussing on the family, and trade unionists on employment, both groups shared a concern for a more widespread shift in values evident in post-1984 New Zealand, while also acknowledging that this shift began in the years preceding the election of the Fourth Labour government. The following excerpt, framed around the issue of employment and the concerns of the trade union movement, is indicative of narrative shared within the collective memory of both mnemonic communities,

Looking back, I suppose, what has been destroyed, I think is that sort of, society caring for itself. That even under [Prime Minister] Muldoon there was quite a considerable emphasis on the individual, right through to the individual and less emphasis on the collective. And that had been going on for some time I think. I mean if you just look at the reforms and industrial relations, the beginning of the promotion of the individual, I think started in the beginning of the mid 1970s, where the concept of the personal grievance was introduced. You know, deal with the phenomenon of injury to one, injury to all. So you know, if you were being badly treated in your workplace, everyone knew about it and everyone would walk off the job in support of you. So this concept of personal grievance was introduced, so your issue became a legal one, and it became private to you, and everyone butted out. That cult of the individual gained strength to the point that when collectivism per se has been effectively destroyed, gradually, but eventually, but the Employment Contract Act, or the undoing of it had started in those '85-'86-'87 reforms.

('Adam', trade union representative).

Repeated use of the word 'destroyed' in both introducing and concluding this excerpt of narrative is reflective of a shared sentiment evident within the collective memory of both mnemonic communities. Again, a discourse was utilised which situates the profane individualism which developed in New Zealand against the sacred notion of collectivism. While the participant frames their memory and evaluation of this shift in values with reference to employment issues, and is collective in nature as it relates to the concerns of the trade union movement itself, it is also collective in its evaluation of the impact on society,

And it's societal. I used to talk about the pay fixing rule, the industrial relations rules through the '70s and early ' 80 s as a piece of social legislation, about modifying behaviours, it was about trying to share-out the gains of society in a fair way, and so on and so forth. But the new social agenda became about the social modification of 
society. So the notion of an industrial relations system being a mechanism for social distribution, ceased. By then, the cult of the individual, which I guess had been growing, sort of just swept ahead. And I've talked to my grandchildren about collectivism and that and they sort of just don't get it. I sort of hope they might, but you know...

('Adam', trade union representative).

The framing of memory within both mnemonic communities, while group-specific in relating to ongoing needs and concerns of each collectivity, therefore shares key evaluative features. Common to both groups was an overarching acknowledgement of a broad shift in values that has an ongoing impact on both the groups of which they are a part, but more importantly families, communities and the collectives they represent through the work in which they are involved.

\section{Mnemonic framing and the negotiation of time}

Moving on from this broad analysis, we find further ways in which the past is framed by both groups of interviewees. Here, framing incorporates the negotiation of time itself in recalling certain events and social movements not immediately related to structural reform. By situating New Zealand's structural adjustments in relation to other social and economic events, participants were able to provide historical context for change, while also painting a picture of a society in flux, shifting through a period fraught with change and increasing tension.

An evenemential understanding of temporality asserts that no event, or period in history takes place in isolation from events or periods which precede it. By situating events in historical and temporal context, participants were able to position their evaluation of certain events, and of the period in question in terms of greater social change. Here, it was not only the events themselves that were of significance, but the participants' use of time as a feature of narrative. By comparing one event with another, participants were able to apply a sense of moral equivalence between certain occurrences of shared significance. To borrow from Zerubavel's (2003) description of 'historical rhyming' in which history is perceived as cyclical, as opposed to a linear perception of history which views historical events as strictly unique occurrences (Zerubavel, 2003: 24); participants adopted a form of mnemonic rhyming. Here, mnemonic rhyming refers to the framing of collective memory in which events are compared or treated as analogous to other events in their factual or material similarities, but 
also in meanings ascribed to both by the group in question. These comparisons relied on an implicit understanding of the significance of one event, as it was used to imply the significance of another.

Using events specific to a given mnemonic community, in this case that of the nation, requires a culturally-specific understanding of the historical event itself and the meaning ascribed to it. The use of culturally-specific simile, analogy and points of reference were therefore central to much of the contextual framework used by participants. The positioning of analogous or comparative events as situated in the past, present, or an imagined future can be understood as emphasising the moral, evaluative and ideological work of participants. An example of this can be found in the use of both time and significant events in the following excerpt of narrative in evaluating New Zealand's structural change,

When you look back in history it was a watershed New Zealand, and it was a way not to do large structural change, but it did do one great benefit and that was that we ended up with MMP. And I think that was one of the things. It just showed you that in the future when you have major structural change, which will come with digitalisation and other things forced on us - global warming, climate change-you have to do things that have a human dimension to it. People do count. And you have to look after people and make sure people aren't crushed in the process. Just basic humanity. And you know, we're very fortunate in our society, that we've had a rather different tradition of non-violence to a certain degree. We haven't had the sort of...like in a lot of societies that have had very violent, with sort of, you know, military control and juntas and that. Not saying that the government hasn't reacted quite sharply when challenged. We had the [19]51 Lock Out, and [19]81...

('Bill', trade union representative).

Here, the participant briefly summarises this period of structural reform and the accompanying social change as being a 'watershed New Zealand' before further evaluating this period as significant in the introduction of MMP (Mixed Member Proportional representation) in 1994, which replaced the former First Past the Post voting system. The participant then continues the evaluation with a nod to the future, implying much can be learnt from mistakes made during this period of radical reform. Interestingly, the participant closes the account with reference to two social and political events in New Zealand's history, the Waterfront dispute of 1951, and the 1981 Springbok tour of New Zealand. The Waterfront Dispute, or 'Lockout' as it is remembered in the collective memory of trade unionists, was the biggest industrial confrontation in New Zealand's history in terms of both how long it lasted, and in the number of workers involved. The Lockout holds particular 
significance in the collective memory of trade unionists, along with the earlier waterside strikes of 1890 and 1913. The 1981 Springbok tour, on the other hand, has broader significance in terms of collective memory, as it transcends organisational memory and appeals to the collective memory of the New Zealand collective itself. Importantly, both events are remembered by each mnemonic community as representing a period of increased tension and division. This research found that the collective memory of New Zealand's structural reform is inseparable from the cultural, social, economic and political significance of several events in the nation's history, with the 1981 Springbok referred to by all participants. 


\section{Rising action: Historical Density and Social Change in New Zealand}

The 1970s - 1980s was a period of extraordinary and escalating change in New Zealand. Beginning in the 1970s, New Zealand's economy deteriorated to a point of crisis, while a new political consciousness developed which gathered groups around issues relating to the race, gender, environmental and peace movements. This period in New Zealand's history can be thought of constituting the rising action in the collective narrative of participants.

A common feature of all the narratives presented by participants of this study was the explanatory and evaluative work of situating the neoliberalisation of New Zealand in time and place, relative to other socially, economically and politically significant movements and events. This feature of narrative - the referencing of a wider social context in which to situate structural reform - was regularly called upon in setting a scene of not merely change, but also tension and drama throughout New Zealand, with the 1981 Springbok tour of New Zealand widely considered by participants as a watershed moment in New Zealand's social and political landscape. In the collective memory of participants, this period of historical density and social change in New Zealand can be understood as the rising action in the participants' collective arc of narrative.

\section{Setting the scene}

Although historical change is a gradual process, with perhaps intermittent periods of drastic transition, the tendency of collective memory is to interpret specific events as symbolic markers of change. While the year 1984 holds the position in collective memory of the nation and smaller mnemonic communities as being a pivotal year for the kind of social, cultural, and economic change related to neoliberal structural reform, participants frequently cited events of significance which occurred both before and after this pivotal point. Just as a purely economic reading of the reasons behind neoliberal reform must take into account economic events prior to structural adjustment, so too must social and cultural change be pitted in its broader context.

Of the social and political change in in New Zealand during the 1970s and 1980s Bruce Jesson writes, 'The student radicalism of the 1960s had left behind a layer of middle-class 
people with a concern for social, moral and foreign-policy issues, who formed the basis for the feminist, anti-racist and peace movements' (1992: 41-42). Significant social events including, issues related to the treaty of Waitangi and the rights of Māori (the Treaty of Waitangi Act, 1975; Bastion Point, 1977-78), the women's rights movement (International Women's Year, 1975), anti-Apartheid and anti-racist movements (Springbok tour of New Zealand, 1981), homosexual law reform (1986), and the nuclear free movement (The New Zealand Nuclear Free Zone, Disarmament, and Arms Control Act, 1987) occurred during a period when the New Zealand economy was increasingly referred to as being at a point of 'crisis'. In terms of the New Zealand economy, 1973 saw the first of two oil crises, the second coming in in 1979, and, importantly Britain's gaining membership into the European Economic Community (EEC). The oil crisis compounded New Zealand's already dire economic situation, and contributed further to post a 1950s drop in the standard of living as the cost of transport and imported goods soared. These, and other events were called upon by participants of this study to provide context and clarity to the social and political climate which gave rise to David Lange and New Zealand's Fourth Labour government taking power in 1984. In the collective memory of both community and voluntary representatives, and trade union members, memory of structural adjustments, Rogernomics and the neoliberalisation of New Zealand is inseparable from the memory of certain events which both preceded and followed the 1984 election. The frequency of socially and politically significant events during this period is described by Eviatar Zerubavel as being a period of 'historical density' (2003).

\section{Historical density in New Zealand}

This clustering of events around the year 1984, both economic and social, and their recollection by participants, positions the year 1984 itself as a symbol of significance. The number of events recalled during this period is what Zerubavel (2003) refers to as a period of 'mnemonic density'. It is this mnemonic density that reflects the significance of the period itself, and how intensely communities remember certain historical periods. Zerubavel writes,

'History thus takes the form of a relief map, on the mnemonic hills and dales of which memorable and forgettable events from the past are respectively featured. Its general shape is thus formed by a handful of historically "eventful" mountains interspersed among wide, seemingly empty valleys in which nothing of any historical significance seems to happen' (2003: 27). 
Events of significance, like those which fill Zerubavel's 'mnemonic hills' of historical density become ingrained in collective memories and provide a constant reference point for mnemonic communities to draw upon as the present requires. Acquiring information about an event second hand, through oral and written histories or informally within the family unit, will never match the verisimilitude of having experienced those events directly. However, through ongoing memory-work, within the communities of which we are a part, memories are transferred, and new meanings may be attributed, or old traditions of meaning reaffirmed. Furthermore, communities tend to draw from events of significance which together mark periods of greater historical density in constructing meaningfulness and significance in past events, but also in the projection of current needs and desires onto the future. The significant event or events are played over in our minds, reconstructed internally and through interactions, but always socially and always within the social frameworks provided by the multiple mnemonic communities to which we belong. Once the event takes on symbolic significance, it becomes a marker for whole societies: there is 'before the event' and 'after the event'. A recent example of this is the Twin Tower bombings of September 11, 2001. The ideological battle we equate with this is not new, and was not new in 2001, but we can all readily attest to how 'the world changed' following this event. Interpretations and meanings may differ between communities, but the event is widely held as pivotal. For the participants of the study, the year 1984 became a symbolic marker of drastic social, cultural, political and economic change in New Zealand.

The following three excerpts of narrative illustrate the historical density of the period in question through the lens of a community and voluntary sector participant. Of particular interest here is not only the density of events, but the focus on events and social movements related to the interests of Māori. As a participant of Māori descent, Māoridom offers another mnemonic community for the participant, understood as overlapping with their membership in the community and voluntary sector,

In terms of the positives of that period, we were going through the period of the Māori Renaissance. So for us there were a lot of positives coming through that. As Ngäi Tahu ${ }^{2}$ we were going through a settlement process, so there was a real drive around that. For others there was the environmental movement...

\footnotetext{
${ }^{2}$ Māori Iwi (Tribe).
} 
...During that time too, in terms of politics, you know, we had Whina Cooper ${ }^{3}$, the Land March, all the protests at Waitangi every year, the [Ngā] Tamatoa Movement of young Māori men striving to get Māori identity recognised. We had Tainui ${ }^{4}$ and Ngai Tāhu working towards settlement and the battles going on there. Manapouri ${ }^{5}$. I mean, we were emerging from quite a lot of political protests. We had the nuclear free movement. So there was a lot of political protest that we were aware of. But, I mean, it was structured around those kinds of issues, rather than issues of equality, inequality...

...There were big social movements, but less understanding of the ground shifting. So the ground was shifting on you, without you even really understanding it, or knowing it. The kind of, the way society was structured was shifting, without you really understanding that that was what was happening. So for me that period was one where the impacts on people was kind of obvious. What to do about it was you responded practically to try to achieve some practical result without understanding that there was perhaps a greater political shift that you needed to be addressing.

('James', community and voluntary representative).

Metaphorically speaking, the 'ground shifting' creates the image of a change of seismic proportions, or a conveyor belt which moves everything against its will or without the knowledge of its passengers, forward into an unknown future, even as significant social movements gain traction in their own right. Bruce Jesson (1992) describes the rise of "the politics of individual conscience' in New Zealand during the 1970s and 1980s, described by one participants as 'a new social settlement,

The women's movement, the Māori movement. All that. It was a new, you know, a new social settlement was emerging... and the anti-nuclear, New Zealand's independence from America...

('Bill', trade union representative).

For women, international women's year in 1975, and that whole '70s period was huge, you know, with the united women's convention and that sort of thing, it was a powerful time. And in education, the '70s were an absolutely inspirational time. They were a time of vision, and I'm talking social democratic vision...

...I attach Mäori renaissance to the '70s and '60s. See I was at university in the late '60s, and Nga Tamatoa was around at that time and by the early 70s when I returned

\footnotetext{
${ }^{3}$ Dame Whina Cooper (1895-1994). A respected Kuia (Māori leader) who fought for the rights of Māori and women.

${ }^{4}$ Māori Iwi.

5 The Save Manapouri campaign was New Zealand's first mass environmental movement.
} 
to New Zealand, I had Mãori friend who had me at Whare Wnagnanga ${ }^{6}$ and that sort of thing. I visiting marae and learning Māori through Massey University. That Mãori renaissance, for me, is earlier. But then you had the development of Kohanga Reo ${ }^{7}$, Māori medium education and that sort of thing coming later. The land march, of I think' '75. So '60s, '70s is where I see it, and by the '80s there was a strong Māori presence in the Springbok tour...

('Jane', trade union representative).

The rise of this consciousness in New Zealand's middle-class, brought about by an increasing concern for moral, social and foreign policy issues, is described by Jesson (1992) as coincidently coming at a time of decline of political interest in the working class. For several of the participants of this study, particularly those with no formal political affiliation in 1984, the mechanics of Rogernomics and New Zealand's structural reform went largely unnoticed in their application. In many ways overshadowed by the various social movements of the time and the want for a change from the old Muldoonism of the late 1970s and early 1980s, it was only when the social cost of neoliberal reform was beginning to be realised that those with little political affiliation began to understand what this seismic shift would mean in the years to come.

\section{The 1981 Springbok tour of New Zealand and a new political consciousness}

The 1981 Springbok tour to New Zealand was repeatedly noted as a pivotal social and political event in New Zealand's history. On the $12^{\text {th }}$ of September, 1980, the New Zealand Rugby Football Union invited the South African Rugby Football Union to send its team, the 'Springboks' to play the 'Allblacks' in New Zealand. Considerable controversy arose within New Zealand from the offer alone, but on the $19^{\text {th }}$ of July, 1981, when the Springboks landed to begin their 57 day tour, New Zealand experienced an unprecedented level of protest and violence in response. Shortly after the tour, Phillip K. Hamlin wrote in the Auckland Law Review,

'The 1981 Springbok tour has been a unique event in the history of New Zealand. Far more effectively than any other single piece of history, the tour has brought into the open the diversity and the strength of feeling that underlies basic principles and practices of our society. The physical intensity of the conflict has to a certain extent polarised the opposing groups. It has also made other individuals aware of the

\footnotetext{
${ }^{6}$ Māori education provider.

${ }^{7}$ Total emersion Māori Language and whanau (family) oriented pre-schooling.
} 
significance of the happenings. New Zealanders have had their "world views" challenged, and some have had to question their own philosophies and "think"' (1982: 323).

The significance of the tour, articulated here by Hamlin, was echoed by participants of this study in setting the scene of a collective besieged by tension, drama and social change,

The only thing I remember as sudden was the 1981 springbok tour. That was sudden and that was traumatic. That was massive trauma. And I don't know if there's any connection between that and what happened later, I suppose there's not, but when you ask me about the ' 80 s, that for me is huge.

('Jane', trade union representative).

I think 81 was the beginning of social and cultural upheaval...

('Susan', community and voluntary representative).

...There was huge unrest prior to 1984. 1981 has to be the symbolic moment, you know? There was a lot of conflict from my perception in New Zealand, and we were...there was a huge number of us involved in some form of action at that time...

('David', community and voluntary representative).

I mean, talking about things I remember, but sitting in the road, moving up towards the blue, red, or whoever they were outside Athletic Park. That was quite unprecedented for me, because I hadn't been involved in...the industrial action we had taken had been boycotts. The social worker group broke the wage freeze by boycotting the courts ... there was a huge number of us involved in some form of action at that time...

('John', community and voluntary representative).

The following excerpt from a community and voluntary representative provides context for the significance of the tour, the cultural significance of rugby in New Zealand, and the tension, drama and trauma associated with this period. The participant begins by offering details which situate the place of rugby in their own personal history,

I was in an interesting kind of position in 1981, because I was a social rugby player here [in Wellington]... I come from a really strong rugby playing tradition. My great grandfather was an All Black and played 3 tests, my uncle played for Otago. The Southern Rugby Club, which was right beside the hill side and those huge railway workshops down in Dunedin was where my father was born, so my whole family had 
really strong rugby roots. As a young child I used to go to Carisbrooke every Saturday and watch the games with my grandmother. It was kind of my life really. And the local rugby club, the Otago team, and the AllBlacks playing down there, because I'm of that generation it was a really, really big thing.

('John', community and voluntary representative).

Details such as these, while autobiographical, are also collective in nature as they describe social and cultural practice shared by a collective. The participant continues to provide highly personal details in describing the personal conflict of being a part of 'that generation' of New Zealanders for whom rugby was felt to be a central component of their identity. One could argue this identity is still very much present in New Zealand today, however, what is important as the participant continues, is the acknowledgment of how the political nature of the 1981 tour called into question this identity, creating a political consciousness for many New Zealanders that had not been present or as pronounced prior to the tour and this period of historical density.

The law firm I was with at the time was really split between senior partners who seemed to be all right wing Tories and the young guys who might have felt the wrath of Muldoon with the tour in 81. I was here in 81 when all that ugliness was going on, so there was quite a tension actually between young people who had just come out of university and our views of the world, and the senior partners who were sitting in houses in Kendallah and drove big cars and had holiday homes. So it was interesting. We had very interesting discussions over Friday night drinks about New Zealand and the society we were living in...

...But, in my social conscience, and of a lot of people I mixed with, albeit they came from similar backgrounds, I guess, we were starting to think about other issues in society. And that was probably...certainly the tour kicked it off. And I wonder if there hadn't been the tour, I'd be quite a different person I think, and a lot of my friends would have been quite different too. If there's had been no tour, then we might not have been involved as a nation, and we might be quite different....

The participant continues to provide detailed autobiographical context in describing the polarising nature of the tour,

... Unlike some of my family, I was an average player, but I enjoyed getting out there on Saturdays. So when it came around to the 1981 tour, you know, there I was, staff solicitor in a large law firm here, and we had the partners who were all off to the games, in the main stand at Athletic Park, and you had us rugby players who were kind of sitting there, but feeling really uncomfortable about it, you know, kind of thinking we shouldn't really go, but we really wanted to go, and there was a bit of a 
division at the office at the time, because we had some really strong anti-tour protestors...

Further information given by this participant provides a personal account of the violence associated with the tour,

A girl that I flatted with at the time was one of the girls who was bashed down here on Molesworth Street [Wellington] down here when there was the riot, and they had the young trainee officers. I remember her coming home from the hospital that night with stitches and gashes above her head and that kind of for me, for our flat, was a really polarising thing. You know, I felt really uncomfortable. It left me with a kind of feeling of deep discomfort. And I still see my old flat mate, and we inevitably go back to that period, to what it meant. She just left the flat and walked down to Molesworth Street to the protest and no one had any idea of what was going to happen. They had all these young recruits because they were short of cops, who were all over the place protecting the tour, and they just had no experience. There was a bit of chanting, and they just kind of lost it really.

The participant concludes by again positioning himself and his family within the tour, and with an evaluation of the meaning of this event in New Zealand's history,

So I kind of remember it as a time... my father and mother had just left New Zealand by then, but my dad was even more of a rugby traditionalist than me, so it was a kind of an interesting period for our family as well, because we had ... I was feeling really uncomfortable about, my other brother was feeling uncomfortable about it, I had another brother in Australia at the time who was kind of divorced from it, you know, because it was... but it was a very, very polarising event in the history of New Zealand, even just to be in Wellington as a so-called 'professional'. It was positioned somehow 'out there' as something the working class, or maybe the trade unions, and certainly the Mãori community were very anti-tour, but it was basically working class guys 'rugby, race, and beers', and all the well to do professionals there too because that was kind of their pass-time, but it wasn't as clear cut as that. It was quite divisive all across society, in different work places. So I remember it being personally a very difficult time.

('John', community and voluntary representative).

Here, three mnemonic communities - the family, the nation and the community and voluntary sector - are called upon in structuring and informing the recollection of the participant within a broader narrative which situates several significant events around the reforms beginning in 1984. Structurally, evoking collective memory of the participant's past through the family as mnemonic community provides autobiographical context for a retelling of a highly personalised and emotional memory of the tour, before placing a broader evaluation of the period within a national narrative reflective of the period, which overlaps the participant's 
social memory as a community and voluntary representative. Highly detailed and emotional responses of this nature, in recalling personally or organisationally-significant events were called upon by participants to effectively signpost the importance of a given episode as being central to the overarching question of the nature and meaning of significant change during this time in New Zealand's history. Furthermore, the participant's highly personal evaluation of the impact of the Springbok tour, and the events that transpired during this time, echo Hamlin's (1982) assertion that this event challenged many New Zealanders' worldview. The participant places the tour in a personal context that would be familiar to many who lived through this time. By offering background information through family history and details of personal circumstances, alongside the memory of a friend physically injured in the violence that accompanied the tour, the participant then evaluates the event as both 'polarising' and for many 'uncomfortable'. Repeated use of the word 'uncomfortable' indicates a level of cultural disorientation which may have been experienced within New Zealand for those whose worldview was put into question, and for a portion of New Zealand society here characterised by the coding 'rugby, races and beers'.

\section{The 1981 Springbok tour as cultural disorientation}

Piotr Sztompka's concept of cultural disorientation (2000) provides insight into the effects of culturally significant events which then become incorporated into a community's collective memory. Sztompka describes 'cultural disorientation' as occurring when,

'the normative and cognitive context of human life and social actions loses its homogeneity, coherence, and stability, and becomes diversified or even polarised into opposite cultural complexes' (2000: 453).

Sztompka notes that the more the event upsets the established order, the stronger the 'shock' is likely to be. This shock to the core of the collective disrupts the group's domain of fundamental values and central expectations (2000). Sztompka also notes that cultural disorientation can occur when a group understands itself as being within a new culture. This arises when the culture, or identity the group carries and understands as their own, is suddenly at odds with the environment the group finds themselves in and as core values and beliefs of the collective are suddenly questioned (2000). These core constructions, which make up the very basis of the group's imagined identity and shape the collective understanding of social issues, come into question, as the group is confronted by a conflicting 
representation of social reality. This understanding of cultural disorientation provides explanation for the deep impact of the 1981 Springbok tour for many of those effected by the violence and conflict, but also for the feeling of discomfort experienced by many who had their deeply engrained cultural values and assumptions questioned.

Opposition to the 1981 Springbok tour unified, if only temporarily, members of many different groups and social movements en-masse for the first time in New Zealand's history, while also polarising opinion in an extremely visible and confronting manner. As coverage of the tour and the accompanying protests was broadcast on television and in newspapers, those not actively involved through physically joining protest movements, or attending the matches developed their own opinions from the comfort of their homes. Crawford writes,

'New Zealanders were confronted with a series of social disturbances, including an account of the New Zealand police using their batons to strike down anti-apartheid marchers. Although the majority may have clung to a tattered philosophy of "sport and politics should be mutually exclusive", the harsh reality of battered heads and flailing batons showed that rugby had become the fulcrum of profound social upheaval' (1988: 112).

The tour became polarising, and through a rugby game, many began to question the legitimacy of a grand narrative which championed social egalitarianism, while welcoming an openly racist organisation onto New Zealand's shores.

I think that if you have a look at all, society was still very much based in the '50s, '60 and '70s, and it was a different culture then than it is now, and I think it was all sort of coming to a head, because of the oil shocks, and all the repercussions of the Brits joining the EU. The springbok tour was also part of the new, emerging generation, that hadn't gone through the Second World War. And that's the whole thing about rugby and its central part in our society. I think that was the key time, and I think with Muldoon something had to happen.

('Bill', trade union representative).

That a series of rugby matches became the vehicle for a broader conversation between New Zealanders about race and equality is fitting when we consider the coding of 'rugby' as a symbol of deeper hegemonic significance. This is touched on by the above participant of this study in his description of the meaning-laden 'rugby, beer and races'; the three pastimes of New Zealand's archetypical straight white male, and of New Zealand's Establishment. 


\section{$5 \quad$ Rising action/Climax: Establishment-New Zealand and the rise of the Fourth Labour Government}

The acknowledgement of drastic change in New Zealand necessitates comparative work in both the personal narratives and collective memory of participants. In the collective memory of interviewees, the years prior to 1984 are often presented as contradictory in nature, giving rise to culturally complex narratives and shared symbols of meaning. While many spoke of the relative equality afforded by the strong pre-1984 welfare state, participants also acknowledged the inequalities of social conservatism and traditionalism under the Muldoon government. Similarly, the relative economic equality of this time was situated by participants within a broader acknowledgement of New Zealand's economy being in a state of crisis through the 1970s and 1980s. These culturally-complex negotiations of memory, in which the past is framed both positively and negatively around certain issues, requires constant interpretative and comparative work by the participants as historical and autobiographical memories overlap to create collective meaning.

Participants spoke of a new political consciousness that developed in New Zealand following a period of relative historical density. The rise of this new political consciousness following years of economic and social stagnation positioned then Prime Minister Robert Muldoon as personifying this stagnation, while incoming Prime Minister David Lange became symbolic of change; of social progress, social liberalism and of any transformation necessary to budge the perceived social and economic inertia. Comparative and evaluative work can also be found as the Keynesian era Welfare state, Social Democracy and the New Zealand that period imbued, is juxtaposed with Neoliberal New Zealand, Liberal Democracy and the social and cultural impact of this sudden change.

Recollections of pre-1984 New Zealand were politicised and often heavily idealised by participants, but were significant in their contextual work and community-specific framing of memory of structural reform. The analysis of comparative work utilises a cultural sociological understanding of the binary codes found within civil discourse which expresses codes along a continuum in their proximity to the sacred, or opposing, profane. A close reading and maximal interpretation of the accounts of participants reveals the hope for change during the 1984 elections as not merely the hope of a nation for economic recovery, but for a changing of the guard: Muldoon representing the Old Establishment, and Lange representing a new, socially progressive and revitalised vision for New Zealand. This 
questioning of hegemonic and Establishment New Zealand, and the rise of David Lange and the Fourth Labour government amidst hopes for social, economic and political change represents the climax in collective memory and narrative arc of participants.

\section{The New Zealand-Establishment}

By 1984 Muldoon's management of New Zealand's social, political and economic landscape had aroused considerable resentment within many groups. As both New Zealand's Prime Minister and Finance Minister, Muldoon relied on tariffs and price freezes to protect the country's economy from changes occurring on a global level, including the oil crisis and the United Kingdom's joining the EEC (European Economic Community) in 1973. The price and interest-rates freeze of 1982-1984 antagonised trade union groups as pay increases ceased, while the workers they represented and their families and communities became concerned with rising overseas debt and increasingly sceptical towards Muldoon's 'Think Big' projects, designed to stimulate the economy. A maximal interpretation of the collective memory of both trade union and community and voluntary representatives reveals how the economic concerns of the time were coupled with a growing resentment for Muldoon the personality, and the Establishment and culture he increasingly came to symbolise.

The term 'Establishment' is used here to denote those who wield the most power in the governing of New Zealand. This includes figures such as key politicians and those in business who are influential in important decisions that have the capacity to shape the interests and outcomes for the country itself (Easton, 1997). What binds this otherwise often loosely related group are the shared interests and networks those of the Establishment share. As such, the Establishment is closely bound to hegemony and 'nation', and a broader sense of a dominant identity within the community in question. The Establishment therefore goes beyond describing the central governance of the country, by coupling power with identity, the social and cultural with the political. Brian Easton (1997) writes,

'Every Establishment tends to look after its own interests and to reflect the viewpoint of its members. The New Zealand Establishment is typically male, older, white, wealthy, middle class and of middle class origin, living in Wellington and visiting Wellington regularly. It is relatively cohesive, because it is small, although there is always ambiguity as to who are on its fringes, who is joining, and who is left out'

(Retrieved from:

http://www.eastonbh.ac.nz/1997/11/the_relevance_of_rogernomics/). 
For participants of this study, by 1984, Muldoon was viewed as embodying not only Establishment-New Zealand and social conservatism, but also a unique brand of socialdemocratic authoritarianism. During the 1970s and early 1980s, Muldoon - seemingly oblivious to the importance of the new emerging political consciousness - provoked a number of groups over his hard stance on the rights of Māori, the 'Dawn Raids' which targeted Pasifika communities, the feminist movement, his indifference over French nuclear testing, and, importantly, his position on the 1981 Springbok tour which saw the tour go ahead. The resentment Muldoon inspired during this era, and the accompanying call for not only economic, but social, political and cultural change in New Zealand, cannot be overstated. A trade union representative described the collective evaluation of changing times by 1984 ,

If we go back to the 1984 election there was an expectation that the winds had changed and they were about to sweep across the country, and this was welcomed, particularly after Muldoon had called the snap election, because we had had enough of Muldoon and enough of strangulation by regulation. I'm thinking in that sort of social area, and in fact, if you look back now, Muldoon was probably more socialist. He was looking after the bloke who - 'Rob's Mob' - as he called them, which were 'ordinary' New Zealander's. He was trying to manage the economy, but people had had a guts full of it I think, so there was a huge enthusiasm when [David] Lange was elected...

('Adam', trade union representative).

Key to this excerpt is the stated 'expectation that the winds had changed and they were about to sweep across the country' and the meaning attached to this change. Here, change relates directly to the widespread resentment of Muldoon, as he is referred to directly, but also social, economic, political and cultural change. Economically, 'strangulation by regulation' refers to the Muldoon government's highly regulated, protectionist economic policies, while reference to 'Rob's Mob' and 'ordinary New Zealanders' implicitly creates a distinction between Establishment, hegemonic New Zealand and those groups excluded from these categories. As Bannister (2005: 2-3) writes,

'Muldoon was a complex figure. A patriarch and a bully, he was notorious for his rhetoric of "ordinary New Zealanders" and his demonisation of "trendy lefties", effete intellectuals, "beady-eyed" feminists, "radical" Māori and anyone else who threatened the status quo with their "imported" ideas' (quotations from Muldoon, 1981 cited in Bannister, 2005).

Again, in Muldoon's own words, a distinction is made between 'ordinary New Zealanders', with Muldoon and the Establishment representing their interests, and those striving for 
change. By 1984, the distinction between this constructed binary along New Zealand's social, cultural and political spectrum was beginning to blur with the advent of a new political consciousness among many of the so-called 'ordinary New Zealanders'. As discussed in the previous chapter, the development of this new social and political consciousness can be understood as resulting from a period of relative historical density. For many of those 'left out' of the Establishment and who increasingly railed against New Zealand's dominant culture, the need for change and organisation around certain social and political issues became a matter of urgency. A community and voluntary representative described the collective sense of need for Māori to mobilise around issues relating to the Treaty of Waitangi, but also the social and cultural climate which gave rise to the sense of urgency during this period,

Much of the politics for us was around Treaty ${ }^{8}$ issues, settlements; that was a lot of the work that we were doing at that time and trying to bring an understanding of Treaty into peoples' consciousness. So our political stuff, for us, if you look at the rhetoric in the paper or on the news at that stage, it was so incredibly racist and antiMāori, it was shockingly bad and if you saw it today, you would just go 'oh my god'. So that was the kind of world I was in...

('James', community and voluntary representative).

This research found parallels between statements such as this, centred on the issues of Māori, and other groups who found themselves on the periphery of Establishment and hegemonic New Zealand. A community and voluntary representative described her involvement in the women's movement in the late 1970s,

Some of that pressure, from my point of view, was around wages. Especially women's wages. And nursing of course. And we had a march down Wellington, it was the only time I'd ever marched...

('Kate', community and voluntary representative).

Another community and voluntary representative spoke of the social climate which fuelled New Zealand's women's movement,

If I go back to, sort of 1975, I was involved in a draw to get a section to build a house. I got the section, the whole lot, but then hit an absolute rock wall because I was on my own and a women wasn't able to sign for a loan. But, by taking it to my father, who had had several coronaries by that point, with his signature on it: that was fine. I was

\footnotetext{
${ }^{8}$ Treaty of Waitangi.
} 
the working one, I was the one that was going to be paying... So we were still getting over, or working through a lot of those things.

('Mary', community and voluntary representative).

The liberal individualism which flourished in New Zealand in the 1970s and 1980s can be understood as both resulting from and contributing to the relative historical density of this period. While much of this liberal individualism, which gave rise to a concern for social and moral issues, can be understood as being a direct result of the student radicalism experienced worldwide in the 1960s (Jesson, 1992), and resulting in New Zealand's feminist, peace and anti-racist social movements, it also resulted in the development of a broader shift in political consciousness indicative of today's socially-liberal democracies. As the new political consciousness looked inward at a nation in conflict between socially conservative traditionalists, and social progressives, understandings of New Zealand's collective grand narrative were increasingly questioned and groups historically omitted from the Establishment and its interests found new allies. With the New Zealand-Establishment and hegemonic New Zealand seemingly under strain, resentment turned toward Muldoon and the National government as groups began to morally position themselves along the sacred/profane continuum of New Zealand's civil discourse and idealised grand narrative.

\section{The sacred and profane in New Zealand's social and political discourse}

Reflecting on this period and the need for social and economic change, participants of this study contrasted the personalities of Muldoon and Lange, as people, political figures, representatives of their respective parties, but also, importantly, as symbolic personalities; representative of a widening division within New Zealand society. By 1984, the divisions within New Zealand which became evident in the 1970s and early 1980s had begun to close following the galvanisation of many groups around certain foreign and domestic issues, culminating in the rise of a new political consciousness following the 1981 Springbok tour. The focus of those effected by this new consciousness - including many of Muldoon's 'ordinary New Zealander's - turned to Muldoon himself. Alexander and Smith write,

'Sacred symbols provide images of purity and they charge those who are committed to them with protecting their referents from harm. Profane symbols embody this harm; they provide images of pollution, identifying actions, groups, and processes that must be defended against' (1993: 157). 
The collective work by participants of this study in contrasting Muldoon and Lange entails the binary coding of each as old or new, rigid or charismatic, conservative or progressive, while casting the 1984 election as a vote between stagnation or change, old Establishment or new guard. The opening statement of a trade union representative is revealing in the equating of Establishment politics with the drastic change that would follow,

\section{It all goes back to the RSA [Returned Services Association] generation and Muldoon's belief that somehow he wanted to look after those people who went through the Second World War like he did. That old RSA, rugby union establishment that was very strong in the post-war period.}

('Bill', trade union representative).

Here, the participant directly equates the generation of New Zealander's who lived as adults through the Second World War, with a hegemonic, rugby-loving New Zealand. This 'rugby union establishment' is understood as distinct from Establishment-New Zealand; however, the two are inextricably bound through culture and shared interests, the former as 'ordinary New Zealanders', or 'Rob's Mob', the latter as Easton's (1997) political Establishment.

The following excerpt is taken from a 1984 Muldoon election speech in which Muldoon largely attempted to rationalise the country's slow economic recovery following a series of significant economic events. The excerpt further illustrates the overt cultural codes of rugby and the RSA which appear as cultural signifiers in the collective memory of participants and the manner in which these codes were operationalised by Muldoon and the National Party during the 1984 election:

'Just a week ago, I stood on this platform in front of the annual conference of the Returned Services Association. They are showing the marks of the years, most of them. I lost five years of my life during World War Two and gained the best education that I ever had. My best friend lost his life in the skies over Britain. I am not going to let him and all the others, or the other young New Zealanders down on this issue. Not I, nor my government, any more than Bob Hawke in Australia, and I say to the leader of the Labour Party and all the other parties, "make it an issue if you wish. I'll stand up to you'.

I have spoken tonight on the principal issues. I come back to the beginning. It is a question of government, it is a question of leadership, it is a question of the team. We know what we are doing because we have been doing it for a long time. I went to the football at Eden Park on Saturday, I enjoyed the game, we won, but I am going to tell you, if this is a testimonial, I had no difficulty in finding my seat". 
(Rt. Hon. Sir Robert Muldoon, Election 1984 Campaign - Opening Address, 25 June).

In this extract of Muldoon's speech, Muldoon recounts his personal experiences during the Second World War and aligns them with that experienced by many of his generation. His closing anecdote regarding attending a 'football' - meaning 'rugby' - match at Auckland's Eden Park appeals directly to 'Rob's Mob', those ordinary, largely working class New Zealanders his government and the New Zealand Establishment would rely on for re-election. As Muldoon put his trust in the mobilisation of New Zealand's Establishment, the 'RSA generation' and a prevailing 'rugby, races and beer' culture to vote for a continuation of the National governments conservative, yet highly regulatory brand of politics, a growing number of New Zealand's population were in search of social and economic change. In order to stay in power, Muldoon would therefore need to discursively align this continuation of leadership with the sacred and pure, and establish the sacred as being in line with the ideals of hegemonic and Establishment New Zealand.

\section{Cultural codes and a grand-narrative under siege}

Complex cultural contradictions were present in the collective memory of participants as they sought to evaluate conflicting ideas of a changing New Zealand. While a common feature of all narratives provided by participants was the prevailing sense of tension and turbulent social change through the 1970s and early 1980s, interviewees also provided narrative which positioned a pre-1984 New Zealand as more in-keeping with New Zealand's constructed grand narrative of egalitarianism, simplicity and the kind of environmental sublimation which gave rise to New Zealand's 'clean and green' brand. The following excerpt of narrative from a trade union representative is indicative of a grand narrative within New Zealand which sublimates the New Zealand experience and culture as traditional, bucolic and pure, while situating the 1980s and 1984 in particular as a point of literal and metaphoric pollution:

It was major upheaval and cultural change. Society had been very stable during the '50s, '60s and '70s. Very stable. Very comfortable. Very isolated. You could go swim in rivers, you could go camping. You didn't have to worry about giardia. You could drink the water. People don't have the amazing...you just didn't have that level of surveillance. Some dreadful things happened, but people could go and do things. It 
was 'Man Alone", the nature of society, where it was very settling, and very based around the farm... But there was also a lot of discrimination, a lot of quite reactionary things around, but in terms of basic welfare, people were probably...people probably had a much better standard of living. It was a much simpler life, without so much consumerism. But all that was shaken. Everything had a monetary value after that.

('Bill', trade union representative).

A maximal interpretation of this passage reveals how the adjectives 'stable' and 'comfortable' can be understood as being laden with meaning in the collective memory of participants. The participant here refers to a mythologised 'golden age' of New Zealand. Easton (2013) found that personal income was relatively stable in New Zealand between 1926 and the 1950s and that income equality improved through to the mid-1980s. This earlier period of stability became regarded as a relative 'golden age' of prosperity in New Zealand, preceding the beginning of economic decline in the 1970s. The participant continues his evaluation of this time in New Zealand's history as being one of both literal and metaphoric purity. A concern for the purity of New Zealand's waterways has cultural, economic and political significance in today's context, as do welfare and basic standards of living. By creating the dichotomy of the past as pure, and the present as polluted, the participant offers further insight into their evaluation of the importance of both basic welfare, and the current standard of living experienced by many New Zealanders

New Zealand author John Mulgan's (1911 - 1945) novel Man alone (1939) is also referenced in the above excerpt in describing pre-1980s New Zealand. Since the novel's publication, the term 'man alone' has been used to denote a certain archetype within New Zealand fiction and culture more broadly. The participant appears to reference this novel in contrasting the rural, bucolic New Zealand of the '50s, '60s and '70s' with what would follow in the 1980s. However, it is worth noting the caveat made by the participant that 'there was a lot of discrimination, a lot of quite reactionary things around'. Various critics of Man Alone have described the novel's male romanticism as chauvinistic, sexist and racist. The participant's use of Man alone therefore becomes symbolically loaded to denote more than merely mythologised past in New Zealand's history, but inherent cultural complexity. Just as a poststructuralist reading of Man Alone can transcend a realist understanding of the novel, so too

\footnotetext{
${ }^{9}$ Set in New Zealand during the Great Depression, Man Alone tells the story of a former English soldier, 'Johnson', who arrives in Auckland during the Queen Street riots of 1932, before later working as a farmhand in New Zealand's central North Island. While working as a farmhand, Johnson accidently kills his employer after an affair with his wife. Johnson then flees the farm and lives rough in New Zealand's hill country.
} 
can a closer reading of the past uncover new interpretations. Man alone may in one sense celebrate a 'robust, direct and honest' style of writing (Evans, 1972: 1), which mirrors the male archetype the novel presents, while also celebrating New Zealand's 'beautiful and terrible landscape' (Te Arama Menzies, 1990: 82), but it also presents the great challenges and hardships posed by this period in New Zealand's history, both socially and economically. Alluding to what has been described as New Zealand's first great novel is therefore a complex, culturally-idiosyncratic reference, which speaks to New Zealand's ongoing and constantly reimagined understanding of its own heritage, history and hegemony.

A community and voluntary representative posited similar, if more overt contradictions, in describing the 'land of milk and honey',

'Rugby, races, and beer', those were the three New Zealand pastimes. That was kind of what the country was founded on. I mean ... and that really harks back to, I mean, my great-great-grandfather came over from Belfast to Dunedin in the late 1860s. They were all basically starving to death in Belfast at that time, and he saw an ad in the Liverpool paper, saying that there were fantastic opportunities out there in Dunedin, so he jumped on a boat with six kids, two of them died on the way over, made it down to Dunedin, and was promised a 'land of milk and honey', and Dunedin wasn't like that all, it was really, really tough. They didn't have time for religion back then, it was basically 'rugby, racing and beer'. That was life in a very male dominated society.

('John', community and voluntary representative).

As seen in the preceding chapter, 'rugby, races and beer' codes the archetypical male Pākehā in a 'very male dominated society'. Mulgan writes in 'Man Alone',

'It was not long before Johnson was at home in this country. He talked as they talked. He got to know the dates of the race meetings and where to get beer in town at most times, and the story of the 1905 match when Wales beat the All Blacks by one try to nil, and why it was necessary to have a farmers government to protect the real interests of the country' (1939: 20).

While participants repeatedly described a New Zealand idealised in its simplicity prior to the 1980s, in its simplicity, the past is also described as socially conservative, traditionalist and homogenous. While participants recalled favourably the social democratic principles, institutions and a general sense of stronger community, autobiographical and historical memory of the deep social conservatism of the '50s, ' $60 \mathrm{~s}$ and ' $70 \mathrm{~s}$ was invoked in setting the scene through narrative, for socially progressive movements that would follow. Without autobiographical memories to call upon to give salience and verisimilitude to assertions made 
regarding the distant past, participants utilised culturally-idiosyncratic codes and collective understandings of a grand narrative that allowed participants to generalise about a mythologised past in New Zealand's history.

\section{The sacred rise of David Lange and the Labour Party}

Despite Muldoon's appeals to the New Zealand Establishment, its rugby-loving public and returned servicemen and women, who, along with many blue-collar conservatives, came to be known as 'Rob's Mob', participants of this study spoke of a prevailing sense at the time that in order for New Zealand to progress socially and economically Muldoon and the National government would have to go. While some participants of this study articulated their vote for Lange as a vote for social progress, others who were not politically active at the time of the election framed their vote as simply a vote against Muldoon, exemplified by the recollection of the following community and voluntary representative:

I remember an increasing number of conversations; it wasn't really about the Labour government, but people were just sick and tired of Muldoon. They hated him with a passion, absolutely hated him. And I remember people saying 'just get rid of Muldoon'. That was it. There was no... media was a whole lot different in those days, all you got was what was heard on the radio, and there weren't a whole lot of stations at the time, all you got was what you heard on radio and what you read in the paper. So in terms of saying to someone, 'well I'm voting for Labour in terms of their policy...' it was kind of, it just wasn't as simple as that. I came from a reasonably well-to-do family, my father was a CEO and was pretty right-wing and Tory, and that's the way Dunedin was: if you had money and you were a professional, you voted National. And Dunedin was a Labour city, it had been a Labour stronghold for years. So for me, it wasn't a policy thing, it was just 'get rid of this dreadful guy. We've got to move on and do something else' really.

('John', community and voluntary representative).

For others, the vote for Lange and the Fourth Labour Government was a vote for social progress, and for David Lange as a symbol of change. Much has been made of Lange in the years following his being elected Prime Minister in 1984. In his obituary in the New Zealand Herald following his death in 2005, Lange was described as having been a 'formidable presence in parliamentary debates, a man of quick wit with a gift for words' (Pickmere, 2003), and his 1985 televised Oxford Union debate has become almost a part of New Zealand folklore when he argued for the moral indefensibility of nuclear weapons. Lange became 
New Zealand's Prime Minister at just 41 years old, and as a relatively young, charismatic and fresh-faced opponent to Prime Minister Robert Muldoon, spirits were high on the Left in the hope of socially progressive change. As Jane Kelsey writes,

'The election of the Fourth Labour government in 1984 made social movements feel more secure. Labour was, after all, the party of the workers, of women, of the peace movement and of the Greens. They promised to - and did - close the South African embassy, tell the French to stop nuclear tests, and declare New Zealand waters nuclear-free. Few social activists knew what Labour's economic policy was, and probably not many cared. Some applauded it, accepting the claims that 'there was no alternative' (1995: 23).

Even as a change in ruling party may have seemed inevitable in 1984, the election itself nevertheless required a substantial amount of symbolic manoeuvring on the part of David Lange and the Labour Party. Of the symbolic work utilised by those seeking power, Jeffrey Alexander writes,

'Taking state power in a democratic society is a struggle for position vis-à-vis the binary discourse of civil society. The goal of those who struggle for political power is to identify themselves, their campaign 'issues', and their broader ideology with the sacred side of this binary and to project convincing accounts of their opponents as embodying anti-civil evil. Those who struggle for power seek to expand these cultural constructions beyond their immediate ideological and organisational groupings, to become iconic objects of emotive identification for populations far and wide' (Alexander, 2009: 68).

For Lange, symbolic significance was found in positioning himself and the Labour Party as trustworthy due to the Party's long history, despite his age, but also as a Party in search of change. Change is an inherent component of any opposition to power, and is particularly present in the discourse and rhetoric of election-time politics. However, in situating the Labour Party as the Party of change, Lange appeals to more than a want of change in government. Change is positioned in opposition to stagnation, creating a change/stagnation binary discourse at a time when New Zealand's economy was often described as 'stagnant' and Muldoon and 'Rob's Mob' were increasingly viewed as a stagnant cultural-relic of oldEstablishment New Zealand, standing in opposition to an increasing number of socially progressive movements. The following excerpt from an electoral dinner speech by David Lange illustrates the performative and discursive work of equating the Labour Party within a change/stagnation binary discourse, 
'Labour is New Zealand's oldest political party. 1986 will be our seventieth anniversary. It is part of the fabric of New Zealand society. It has a breadth of experience and a depth of tradition which is unparalleled in New Zealand history.

But it has a resilience which belies its maturity. During the general election campaign and the round of party conferences we looked like New Zealand's youngest and most energetic political party. And that is the nature and strength of the Labour Party. We are always renewed...

The Labour Party was founded on the commitment to change. It is the instrument of change and in changing New Zealand it has changed itself so that it makes political parties which are much younger than itself look tired and irrelevant'

(Rt. Hon David Lange, PM Western Hutt Electoral Dinner, 11/12/84).

Here we see the 'energetic', 'renewed' and 'committed to change' Labour Party, a party which seemed young in its enthusiasm, cast against the 'tired and irrelevant' National Party. 'Change', however, could not merely be positioned as a binary opponent to 'stagnation' in order to convince a collective of the need for a change in government. In order for Lange to be elected, an effective performance of the need for change had to convince the audience of the dangers of continued stagnation. During an election, Jeffrey Alexander argues, a nation must be convinced that they face a unique moment in their history. This involves the construction of a cultural framework which,

'declares unprecedented dangers and opportunities, domestic and international troubles that threaten to derail the nation's triumphant mythical history. As "The Dream" lies in tatters, the present moment is precarious and burdened with terrible significance. Desecrated and polluted - not least by the outgoing administration - the nation must be purified. For this we need a hero; only one man [sic] can save the day' (Alexander, 2010: 17).

Talk of the economy as being in a stage of crisis was rife leading up to the 1984 election, and was seized upon by the Labour Party to further Labour's positive position in the change/stagnation binary. Again, Lange's electoral dinner speech is telling of this discursive positioning:

'This fall from grace is the stuff of tragedy, and it is twice a tragedy for New Zealand. It is first a tragedy because it need not have happened. The warning signals have been there for many years. Our economic performance has been deteriorating since the end of the 1950s, long before the oil shocks of the 1970s brought us nose to tail with crisis in our balance of payments. Even when the National Party government thought that it could borrow its way out of economic difficulty. It had the easy answer, the Think Big projects. 
That government said to New Zealand, don't worry, don't change, we'll borrow for the big projects and when they come through you'll be better off without working for it.

"Think Big" was not the answer. The projects are not going to come through. The deception wore increasingly thin until finally it could not hold.

That is the first tragedy, the tragedy of lost opportunity.

The second tragedy, and the greater, is what that poor economic performance has done to the social fabric of New Zealand. There is poverty and inequality in New Zealand where neither should be tolerated...'

(Rt. Hon. David Lange, PM Western Hutt Electoral Dinner, 11/12/84).

The 'tragedy' Lange speaks of here is on two levels: the economic, and the social. By positioning himself and the Labour Party as the party for change, Lange equates stagnation, or the continuation of the National government's time in power, with the 'tragedy' of New Zealand's social and economic crises. Participants of this research from both trade union and community and voluntary groups spoke of a political climate within New Zealand which pitched Muldoon as embodying both economic and social stagnation, and of the hope for change as Lange embarked on the campaign trail. The success of Lange and the Fourth Labour government therefore relied on the successful positioning of Lange, the Labour Party, and the change they advocated, with a new, sacred narrative of social progress.

\section{Flashbulb memories and the process of meaning-making}

Participants' narratives took highly personal turns, and flashbulb memories were evoked as they sought to attach greater meaning or significance to certain events or the period of time in question. These accounts are easily distinguishable from the broader narrative of which they are a part, both in terms of their highly personal nature and detail, but also in terms of structure. Broadly recalled memories of this period, as has been shown previously, were often fragmented, yet cohesive in their social framing; trade union representatives consistently framed their recollections in terms of (un)employment, while community and voluntary representatives' memories were framed around family and community. Instances of flashbulb memory were often more difficult to place within the participants' broader narrative in terms of their overt meaning, however a maximal interpretation of these highly personal memories reveals their collective significance and positions them firmly within the collective arc of narrative. Furthermore, far from premeditated, instances of flashbulb memory seemed to 
occur more out of a kind of stream-of-consciousness, as objective recollections along the 'party-line' gave way to highly subjective emotions, and memories which participants felt best captured these feelings.

The interspersing of highly personalised and emotive memories among more formal or official voices of the group or organisation have the added effect of mixing both 'official' and 'vernacular' voices (Schudson, 1993), substantiating the claim that collective memory 'lives with greatest strength in those forms that bring public event-memories and private memories together' (Wagner-Pacifici, 1996: 312). Further, this distinction between 'public event memories' and 'private' memories, and the associated 'official' and 'vernacular' language this research has identified as respectively being indicative of the two, falls in line with Maurice Halbwachs' sharp distinction between 'autobiographical' and 'historical memory' (Halbwachs, 1992). Many of the accounts recalled by participants may best fall under the 'historical' category of memory, as Rogernomics and the neoliberalisation of New Zealand has undergone increasing scrutiny over the last 30 years. However, autobiographical memories of their very nature must be shared and rehearsed, often with other members of the individual's given mnemonic community, in order for them to survive. It therefore follows that given the freedom and time to explore their memory, the individual may on their own accord provide an example of 'flashbulb memory', which, in its inherent significance, provides the grounds for a maximal interpretation of the event in question. That is, even if autobiographical memories, and flashbulb memories in particular, are not shown to be factually accurate, or cannot be corroborated by the group, their very recollection provides the kind of saliency for a rich process of interpretation which seeks to draw significance over and above the details which are recalled.

A community and voluntary representative conveyed an instance of flashbulb memory that illustrates both the popularity of David Lange leading up to the election, but also the perception of Lange as a 'man of the people', which has become a part of the national collective memory,

I remember Lange because I was driving through the village and there were a lot of people hanging around the village hall. So I pulled over and wandered over to see what was going on, and I asked what was happening and they said they were waiting to see 'that guy from Labour. The candidate for Prime Minister'. So I hung out in the foyer of the hall and a car pulls up and Lange pops out and he comes into the foyer and his man goes up to the front of the hall to introduce him and me and Lange are standing in the foyer looking at each other, saying, sort of ' $g$ 'day'. And then the guy 
introduces him, he goes up, does his 'soap-box' talk in the hall, and out into the car again and off to the next village. Yeah, I remember that well...

Structurally, this memory of a brief encounter with Lange takes the form of narrative indicative of storytelling. The informal nature of this chance encounter and the casual greeting of ' $g$ ' day' upon meeting further emphasises the perception of Lange as approachable and likeable, cast against the notoriously difficult Muldoon. The participant continued,

...Lange was a talker. So he was talking, as well, to rural New Zealanders who wanted to come and see him. And there were a lot. I mean, that hall was full...

...I don't remember his talk, but I remember that he was a talker. And he had his patter, people going 'yee-ha!' And he did. He came to represent a Labour party that was interested in people. It was exciting. It was a difference. It was a change...

('James', community and voluntary representative).

The perception of David Lange at the time, leading into the election, is evident in this instance of flashbulb memory, but is also indicative of a broader image of Lange which exists in the collective memory of the New Zealand public. These types of memories of Lange as a charismatic and personable leader were coupled by participants with overtly political hopes and expectations for broader, socially progressive change in New Zealand. A trade union representative and feminist who was politically active in the Labour Party at the time of the 1984 election described the sense of optimism shared by all participants of this study:

So that whole thing as a woman, a feminist, you sort of move from the women's movement, into the [1981 Springbok] tour and all the huge passion of that time and then on into '84 and the hope that we had with Labour; the absolute hope that we had. You know, we were going to have... all sorts of exciting things were going to happen...

... So the Labour party continued with a socially progressive narrative, coupled with an extremely economically-conservative policy platform. And that was one of the things that kept some of us in, because you wouldn't get that socially advanced kind of agenda that included recognition of women's goals, and later of course the LGBT and rainbow movement within the Labour party...there was that feeling that the Labour party was the place where you could get progress.

('Jane', trade union representative).

This sentiment of hope and excitement, whether with regard to the goals of a specific social movement, a broader development of political consciousness, or simply out of resentment for what Muldoon came to symbolise was shared by all participants of this study. In the collective memory of both community and voluntary and trade union mnemonic communities 
a collective arc of narrative saw the development of social individualism and a new political consciousness increasingly calling into question hegemonic and Establishment-New Zealand. Following this collective arc, the new political consciousness that developed in New Zealand can be understood as resulting from a period of relative historical density in New Zealand during the 1970s and leading up to the election in 1984. The election of 1984 saw a struggle for position within the binary discourse of New Zealand's civil society, but also with reference to New Zealand's constructed grand narrative. Culturally complex contradictions were apparent in the individual narratives presented by participants, with interviewees seemingly conflicted between the necessity of a socially progressive turn in New Zealand's social and political landscape, as this turn is associated in the collective memory of participants with the adoption of right-wing structural adjustment, which has had a lasting impact on New Zealand society. The collective arc of narrative which constitutes the collective memory of participants shifts from this challenge to hegemonic and Establishment New Zealand and culminates in the collective memory of the realisation of Rogernomics, the neoliberal agenda, the impact of structural reform, and the betrayal of New Zealand's Labour Party tradition. 


\section{Climax/falling action: The Realisation of Rogernmomics}

Continuing the collective arc of narrative to the falling action stage, participants presented the collective memory of the realisation of structural adjustments and its impact on New Zealand's Labour tradition primarily through instances of flashbulb memory. Recalling David Lange defeating the Muldoon government and elected as Prime Minster in 1984, participants of this study reiterated the collective feeling of hope - that the winds had finally changed and that a new government, led by Lange and sympathetic to the new political consciousness which had developed in New Zealand, had finally come into power. The change that would follow the election of the New Zealand's Fourth Labour government, however, took the form of sudden and drastic structural adjustments which signalled the beginning of the neoliberalisation of New Zealand and which would have a profound impact on the social, political, cultural and economic landscape of Aotearoa New Zealand. Moving into 1984, and through the two terms of the Fourth Labour government, which spanned from 1984-1990, the collective memory of participants of this study, from both community and voluntary, and trade union mnemonic communities, indicate the realisation of a new, neoliberal reality as having a profound and lasting impact on New Zealand society, but also the Labour Party tradition.

\section{The changing winds}

The year 1984 and the years of structural adjustment were again recalled by participants as being a pivotal point of change, with the 1970s and the early 1980s regarded by interviewees as a simpler time in New Zealand, before 1984 signalled the beginning of increased technological, social and economic change. However, for those who were politically active or affiliated during this period, the realisation of the impact of neoliberalisation in New Zealand is inseparable from the frequently cited feelings of shock, betrayal, and trauma associated with the realisation that it was New Zealand's traditionally socially -progressive Labour Party which was responsible for drastic right-wing adjustments which began in 1984 . The highly personal nature of emotions associated with this sense of trauma and betrayal necessitate a switch in the tone, detail and structure of narrative, as participants sought to identify and attach suitable meaning to moments or events which best illustrated the most impactful thoughts and feelings they associate with this period. A community and voluntary 
representative who was active with the Labour Party at the time of the 1984 election recalled the collective sense of euphoria experienced at the Party's victory conference, but also of a broader sense of shared hope and excitement shared by all participants,

Oh it was euphoric. That theme song kept being replayed, everybody was happy, [following] the conflict and the uncertainty of what seemed to be the Muldoon era...the conference was large, the worker's flag was crimson red, and it had that feeling of a movement. Like "Here we are. This isn't right. Now we can really fix this"”.

('David', community and voluntary representative).

Inherent in this participant's recollection of the victory conference is the juxtaposition of the 'conflict and uncertainty' apparent in New Zealand under Muldoon with the euphoria of a hope for change and the implicit evaluation of change as likely to herald a period of agreement and certainty. The participant's memory of the 'worker's flag...crimson red' is recalled as symbolic of the Labour Party, of the left, and of the trade union movement. The image of the crimson flag evokes the impression of unity and of traditional values associated with the Party, while the plural pronoun 'we' in the statement 'Here we are. This isn't right. Now we can really fix this' invokes not only a sense of unity, but a determined sense of purpose. Much of this sense of unity and hope was expressed by participants as in large part maintained by the continuation of support by Lange and the Labour Party of the various social movements which had ascendency during this period, illustrated here in an excerpt of narrative from a trade union representative:

I suppose their first term was not as revolutionary, you could see the signs of it, but there was the Waitangi tribunal, nuclear free stuff, there was all this good stuff happening, and people were sort of swept along by it.

('Adam', trade union representative).

Repeated metaphorical imagery presented by participants including hopes that the 'winds had changed', that the 'ground was shifting beneath you' and, above, that 'people were sort of swept along by it' speak volumes in the collective memory of participants to not only the historical density of this period, but to the considerable change that would come with the election of the Labour Party in 1984. In the collective memory and narrative arc of participants, the sense of unity and euphoria was short-lived as the reality of the encroaching neoliberalisation of New Zealand took hold. In large part, the delayed realisation of plans for right-wing structural adjustments was recalled by participants as partly owing to the continued narrative presented by Lange and the Labour Party in support of issues at the 
forefront of the Left and the new political consciousness in New Zealand, coupled with a narrative that positioned economic adjustments as necessary given the climate of crisis. A trade union representative recalled this coupling, in retrospective evaluation, as political spin,

I think the public was getting the spin. You know, because the union movement was particularly visible through the media. The public was getting the spiel that we've got to do this, it's for our own good, and there wasn't much resistance really. And that was evident I think in the second election when Labour returned with an even bigger majority. And labour had done some good stuff in terms of the nuclear free and some other things...

... What did the spin look like? It looked like confidence. Lange was a good sales person, there was no doubt about that. He had charisma, he had presence, and they seemed, Roger Douglas ${ }^{10}$ particularly seemed to be managing the economy pretty well and talking about surpluses and stuff in a short space of time leading into the second election...

('Adam', trade union representative).

The socially progressive and economically positive narrative indicated here, in which social progress and economic recovery are coupled, was evident in many of the speeches and media statements given by David Lange leading up to the 1984 election, and going into the Labour Party's first term,

'The Government is determined to follow a path of social reform which will eliminate poverty from New Zealand and ensure that individuals do in fact enjoy equality of opportunity. That means that there must be fairer shares than there are now in the wealth of the whole community. It is difficult politically and socially to achieve that process of redistribution when the economy is not flourishing. The outcry over the surtax on national superannuation tells you what I mean. It is economic growth which prepares the ground for social justice.

The economic policy of the Government is designed to encourage change which will lead to economic growth. We are creating a climate in which investment will flow into productive export and import substitution areas. We are eliminating the subsidies which propped up vested interests at the expense of all the rest of us...

...The Labour Party cherishes as it has always cherished the worth of every individual, and derives from that worth the responsibility of the whole community towards the individuals who are a part of it. That is what in the Labour Party will never change, however much the Labour Party alters. We shall become mechanics to the economy if that is what it takes but we know why we want the economy to work. Once again a Labour Government has set out on the course which will eliminate

\footnotetext{
${ }^{10}$ The fourth Labour government's Minister of Finance, 1984-1988.
} 
poverty and (promote) social justice. The Labour Party knows that course of old and it is the strength and courage of the Labour Party that will get us there'

(Rt. Hon David Lange, PM Western Hutt Electoral Dinner, 11/12/84).

By coupling the social and with the economic, in this speech Lange makes clear even as the economic situation must be addressed, the Labour Party will not deviate from its traditional, socially-oriented position. Lange directly associates the individual with the sacred collective, and reassures the Party's followers that the 'responsibility of the whole community to the individuals who are a part of it...will never change, however much the Labour Party alters'. Lange continued,

"But I tell you this. I said when I started tonight that hope without reality is frivolity. Reality without hope destroys the soul. The new Labour government has faced reality but we are confident in our hope for the future. New Zealand's economic difficulties are not obstacles. They are opportunities. The party of change will once again change New Zealand but we shall keep what matters to New Zealand"

(Rt. Hon. David Lange, PM Western Hutt Electoral Dinner, 11/12/84).

It is clear from these excerpts of Lange's speech that he pledged to maintain both the sacred, traditional principles of the Labour Party, and what can be understood as the sacred, collective values of wider New Zealand. A maximal interpretation of the collective memory of participants of this study also revealed a collective hope for not only economic recovery, but of social progress with the election of the Labour Party. However, a close reading and maximal interpretation of instances of autobiographical memory reveal highly personal recollections of moments of realisation and evaluation which takes the collective arc of narrative to the stage of falling action.

\section{Early signs of a culture-shift}

Participants spoke of the early realisation of the impact of structural adjustments and its social and economic implications in the immediate world around them. Several spoke of the appearance of a new form of ostentatious wealth previously unseen in New Zealand, as illustrated in the following excerpt of narrative provided by a community and voluntary representative,

I was very conscious that there were people in Wellington at that time who were making amazing salaries, you know, that they were involved in these sort of things. I was aware of these guys my age who had just finished the financial year, and had got 
a bonus, and had bought a new house, or this or that. So for those of us getting meagre wages at the time it just seemed like incredible riches. So we knew that something, someone, was making a hell of a lot of money out of what was going on...

('John', community and voluntary representative).

Similarly, another community and voluntary representative spoke of the rapid economic and technological changes experienced during this time:

We also went through some little boom periods where for some and for society it was a successful time. And it was a period of other change as well. So if you like, pre '86, who had a computer? No one had a computer; no one had a mobile phone. By 1990, everyone's walking around with 'bricks', and that's part of the whole societal change we were seeing. It also became fashionable to flaunt your wealth; in the 1970s, less so. Much, much less so. So that all feeds into the personal responsibility and 'look at all the good choices I made'. It was quite a different approach to life.

('James', community and voluntary representative).

The two excerpts of narrative above are both from community and voluntary representatives who were not 'politically active', as this paper defines it, during the period in question. What is clear from their shared memory, however, is the evaluation of 1984 as heralding a shift in culture which moved beyond the need for economic recovery emphasised by Lange and the Labour Party. The coupling of the rise of ostentatious wealth, where it 'became fashionable to flaunt your wealth', with the rise of the cult of personal responsibility indicative of neoliberalism was expressed by participants as being a profanation and polluting of the kind of collectivism indicative of Keynesian-era New Zealand, and a perversion of the rise of social individualism inherent in the emerging political consciousness of the 1970s and ' $80 \mathrm{~s}$.

\section{Realisation as falling action}

Highly emotive and personalised memories increased in frequency in the recollections of participants as the collective arc of narrative in recalling this time developed to the stage of falling action, or the realisation of the beginning of the process of neoliberalisation and the deterioration of New Zealand's Labour tradition. A community and voluntary representative who was politically active with the Labour Party at the time, recalled a highly personal and emotional instance of flashbulb memory which exhibits the evaluative and meaning-making work participants drew upon in recalling highly personal memories. In this excerpt the 
participant recalls the Labour Party's 'rapturous' victory conference and the popularity of David Lange in 1984,

I went to the victory conference, right? 'The Wind beneath our Wings'... It was absolutely rapturous. I would say Lange was at the height of his powers, and so was Jim Anderton ${ }^{11}$. He had absolute control and the loyalty of a very large group of delegates in the Michael Fowler Centre and we were the government. And Michael Cullen ${ }^{12}$ was winding up, he was the Chief Whip at the time, and he arranged for the delegates - I thought it was a brilliant move - on the Sunday morning Michael Cullen invited delegates to choose which minister of the new government they would go and sit in their office, in the Beehive ${ }^{13}$, our government, and talk to the minister for ninety minutes or something. It was to get discussion off the floor of conference, but none the less it was a wonderful event...

('David', community and voluntary representative).

In this passage, while autobiographical in nature, the participant expresses the collective sense of joy expressed by all participants of this study at the victory of Lange and the Labour Party. The image of the victory conference itself is one that has remained in the collective memory of the national political consciousness like no other in the country's history.

Reference to 'The Wind Beneath our Wings', not only alludes to the theme song played at the victory conference, but also echoes the statement referenced earlier that there was a sense that 'the winds had changed' in New Zealand. The participant's use of the pronoun 'our' and plural pronoun 'we' indicate a perceived sense of unity in the Labour Party prior to 1984 and the collective sense of accomplishment and hope after having won the 1984 election. The participant's assertion that ' $w e$ were the government', and his mention of the Beehive, Wellington's House of Parliament, immediately followed by the qualifying 'our government' further emphasises the collective sense of shared investment and involvement in the incoming Labour Party.

It is clear from the above excerpt of narrative that hope and confidence in David Lange and the Labour Party was high at the victory conference, but as the participant continues, for many the realisation of what this change would herald, was stark. Invited to choose a minister to sit with and discuss the direction of the new government, the participant chose to sit with Roger Douglas, the architect and namesake of what would become known as 'Rogernomics':

\footnotetext{
${ }^{11}$ Member of the Fourth Labour government, 1984-1989, before resigning to create the NewLabour Party, and later the Alliance Party in 1991.

12 The Fourth Labour government's Senior Whip in 1984, and later Associate Minister of Finance in 1987.

${ }^{13}$ Common name for the Executive Wing of the New Zealand Parliament Buildings.
} 
...I went to Roger Douglas' office to talk to him. I had been told that Lange's room was absolutely packed, and Russell Marshall's ${ }^{14}$ was packed with delegates, and there were ten in Roger Douglas', which I think was very eloquent in itself. And there was Trevor de Cleene ${ }^{15}$ sitting beside him with his bone-handle walking stick banging on the floor emphasising to the delegates that there would be no subsidies. And I asked if there would be subsidies because I come from an area where farm subsidies basically kept it all going, and Trevor de Cleene was asked what was going to happen to those communities, and he said 'no, no, we have to bite the bullet and go through with it', and Roger Douglas was absolutely clear about the programme that he was going to institute. And he gave it out in writing, he was absolutely clear and straight forward and I realised pretty much then that I was in the wrong political party. It was very, very astonishing, and from there I never believed a word Lange said about being jumped and surprised. To me it was an astonishing coup. You can see in hindsight now, but that realisation was huge, and very disorientating because I thought that this was me and suddenly the party was gone. Jim Anderton took a couple of years to realise it, but he came to the same conclusion.

('David', community and voluntary representative).

Here, the participant's narrative moves from the 'rapturous' 1984 Labour Party election victory conference to the realisation of both the beginning of dramatic structural adjustment which would follow, but also the readjustment of New Zealand's Labour Party and the sense of betrayal experienced by many of the party faithful. The shift in tone of this memory follows the description of Trevor de Cleene's 'bone-handle walking stick banging on the floor', creating a turn in narrative from the rapturous, to the 'astonishing' and 'disorienting'. Use of several pronouns also positions the participant personally in the election win, while the quote attributed to Trevor de Cleene 'no, no, we have to bite the bullet' can be understood as further emphasiing this turn in narrative which precludes the evaluation by the participant of the 'astonishing coup' which deeply divided the Labour Party. Again, the participant's own evaluation of this memory as being pivotal in their realisation of the social, economic and political significance of adjustments beginning in 1984 is made explicit with the assertion that 'suddenly the party was gone'. A maximal interpretation of the autobiographical memory of this participant, and in particular this instance of flashbulb memory, indicates how highly personal and detailed forms of autobiographical memory can underscore powerful

\footnotetext{
${ }^{14}$ Fourth Labour government's Cabinet Minister in 1984-1990, Minister of Education, 1984-1987, Minister of Foreign Affairs, 1987-1990, Minister for the Environment, 1986-1987, Minister of Disarmament and Arms Control, 1987-1989, and Minister of Pacific Island Affairs from 1988-1990.

${ }^{15}$ A supporter of Rogernomics and appointed undersecretary to Roger Douglas. De Cleene resigned from cabinet after the ousting of Douglas.
} 
significance for the wider mnemonic group as the broader significance of this memory has continued ramifications for the community and voluntary sector, the Labour Party and New Zealand society.

Similarly, the following instance of flashbulb memory conveys not merely a participant's memory of the announcement of the proposed Goods and Services Tax (GST) at the Labour Party Conference in 1985, but the broader significance and meaning attached to this event as being symbolic of the greater impact of Rogernomics:

Oh look, you can't believe what it was like, I guess, unless you were there. As a young person I thought everything until 1984ish, everything we did in the Labour Party conference, everyone felt connected together, we all supported the same policy. That period, you could have put a knife through the Labour Party. And I remember thinking 'fuck, this isn't my family anymore. This isn't the people I connect with. I can't stand here and listen to this, and all these grey suited men'. I remember this image of Roger Douglas and all those men standing up and announcing the GST thing. It seemed to me they were all in the same suit, and there wasn't a woman amongst them, and I thought 'I can't be here'. I was working for them, but I can remember thinking 'you're ruining our country. You're doing things that the people don't want'. So it was quite powerful at the time...

...They shafted us big time, those men. Do you remember that? Have you seen that photo? I always will. I have it etched in my mind. And that conference was just so divided...

The participant continued with her evaluation of the metaphoric significance of the 'greysuited men' present at the announcement,

...For me, I think it was complete...well, I think it was Roger Douglas and Richard Prebble ${ }^{16}$, it signified a complete travesty of what we really believed, which was social justice. That's what it signified, for me, if I have to put it into words. I've never put it into words before, but that's what it signified for me. All those grey suited men, standing in a semi-circle, telling us that we were going to have a GST. I think that's what it was. And it was like, 'you've just stepped away from...we don't believe that's good for the people', you know? More tax, more... and obviously it was caught up in the whole - I'm trying to stretch back my mind - it was more of this corporatisation. The good old socialist principles had gone. The good old values, I don't know, of people. You know?

\footnotetext{
${ }^{16}$ Fourth Labour government's Associate Finance Minister and supporter of Douglas. Alongside Douglas, and David Caygill (Minister of Trade and Industry, and Minister of National Development in 1984), Prebble was responsible for most of the economic reforms associated with Rogernomics. Together the three were dubbed 'the Treasury Troika'.
} 
...The image was corporate, and ughh ... and I remember other people around me reviling. It didn't symbolise the Labour Party. It wasn't our Labour Party. It was a takeover by Rogernomics, and all the people in the room were people who supported him, and they were all white men, and they were ugly. Quite simply ugly. And I mean, this stayed with me, and that was my trauma. The Labour Party conference itself was trauma. You'd never seen anything like it...

('Karen', trade union representative).

In this account the 'grey-suited men... standing in a semi-circle' are significant in more than merely the announcement of a new tax which the participant opposed politically and in principle, as GST was predicted to impact those in low-income jobs and large families the hardest. The 'grey-suited men' stood united in metaphor, a representation of a new political landscape and a travesty of the traditional position of New Zealand's Labour Party. Furthermore, in the recollection of the participant, the grey-suited men represent the archetypical business-man: white, male, bland, and 'ugly'. This representation of the 'business-man' is central to the concept of the 'Establishment' discussed previously, and the image evoked in this memory indicates a perceived continuance of Establishment politics and hegemony during a period of relative social progress and of hope for change. The participant recalls this instance of flashbulb memory as a turning-point of evaluation and realisation which encapsulates the broader position of the trade union mnemonic community in their evaluation of the social and political impact of Rogernomics, neoliberalisation and the fracturing of New Zealand's Labour Party. Further maximal interpretation of the significance of this recollection and its meaning pits the pure against the polluted as democracy is understood as being 'corporatised' and the core principles of the Labour Party are compromised.

Participants showed signs of attempts to rationalise the implementation of drastic structural adjustments, as they struggled retrospectively to make sense of their memories of collective betrayal and cultural disorientation. A trade union representative described how the early sense of unity felt by Labour supporters quickly turned to distrust amidst conflict within the Party itself:

I think there was a readiness, and I'm thinking around the Labour movement particularly, a readiness to embrace the new Labour way, of whatever way shape or form. So when Labour started to come up with some of its early reforms, it was, we were saying 'well it must be good for us, in some respect [laughs], because it's different' and 'we didn't vote this government in to have them shaft us'. There was that idea of trust. So that was part of the conversation, and I think the other part of 
the conversation was that I think I remember saying 'well, no. They're untrustworthy bastards' you know 'this isn't good. This privatisation agenda, or whatever you want to call it, won't be good for us'. So there were two conversations going on at the time. And I can sort of remember people at the time saying 'well, we need to cooperate with this government, because it's the best government we've got' and others of us were saying 'no, we don't need to [laughs], you know, we've got to stand on principle', and I guess that was a point of difference.

('Adam', trade union representative).

The participant here presents a dichotomy between those who followed the Labour Party in their implementation of right-wing economic policies, and those who would 'stand on principle'. This collective sense of trust expressed by the above participants was evident in the narrative of all participants and is crucial to the collective memory of participants in creating the falling action and evaluative component of the collective arc in narrative. This sense of trust in the Labour Party and their history of championing social democratic principles, coupled with Lange's willingness to engage in dialogue and address concerns of a new sense of a social justice in New Zealand was collectively expressed by participants as being integral to the sense of shock and betrayal that would follow.

\section{A party divided}

The divide within New Zealand's Labour Party became increasingly apparent as party membership fell from 45000 prior to the 1984 election, to 11000 in May 1988 (Kelsey, 1995: 36). 1989 saw the party split with the formation of the NewLabour Party, led by then MP and former Labour Party president Jim Anderton. The division within the Labour Party and the formation of NewLabour was significant in the memory of all participants politically active during this period. However the significance of this division can again be found in an instance of flashbulb memory. The following excerpt of narrative from a trade union representative illustrates both the metaphorical and literal division of the Labour Party and the Left in New Zealand following radical reform:

I remember going to this conference, and Lange was there, and nuclear policy was one we all still felt united around. I remember no one would go up and talk to him, and he was this very lonely figure in the room. And I remember going up to Jim [Anderton] and saying 'no one's talking to David Lange. He looks lost. He's the Prime Minister', or whatever [laughs], 'what do we need to do?' And everyone said 
he was a bit like that, you know? 'He doesn't engage with people...' blah blah blah. And we tried to go up and have a conversation with him about it...

...I just felt he was really isolated, and I guess in some ways he looked like a lonely man. I don't know that his heart was with the Rogernomics crowd, really, in some sense. He couldn't find...no one was with him. He came down to talk about 'nuclear free', that was around that time, and I remember thinking 'here's our leader, but he's lost in space', if you can think of it like that. I don't think he was quite there. I mean, Roger was probably always trying to shaft him, and then you had the Left. So he was actually...no one was talking to him, not even the people who might have been the Rogernomics people. So he was isolated, and still trying to champion an important issue, but he had lost control of the economics, and that's what I saw....

Here the participant describes the image of David Lange as 'isolated' and as a 'lonely man': a literal Man Alone. The image of Lange alone is symbolic of New Zealand's irreparably fractured Labour Party, of Lange's complete loss of control of the government's direction, and of a loss of faith placed in him by New Zealand's Left. The participant continued,

...I just saw this person that no one could find a way to talk to, because people had probably divided into camps. And while he was in that photo...I think I remember there was agitation in trying to remove him from the leadership. So there was a lot of people agitating against him. But he looked lonely, aloof, and for someone that leads the country, people should be rushing up to shake his hand. But no one went near him. Nobody. Maybe he was having his affair [laughs]. Maybe he was wishing he was somewhere else and didn't want to talk, but there was definitely...it's not what you'd expect when you see a leader. Maybe he had lost belief in the party himself and just couldn't put any energy into it himself and engaging with people. And I remember saying to Jim, 'god. Do you think someone should go talk to him?' I think I managed about 30 seconds, because we were all young and thinking 'why aren't all these other people talking to the leader?'

('Karen', trade union representative).

The symbolic significance of Lange alone in the memory of this participant was one which resonated with several participants; not in the detail of this autobiographical memory, but in the shared significance of his being alone as a symbol of a lack of confidence in Lange, the takeover of the Labour Party by right-wing reformers, the deep divisions within the Party itself and divisions within the Left more generally. Several participants, politically active during the Fourth Labour government's two terms in power, echoed this deep divide, as illustrated in the following excerpt by a trade union representative:

Well I think it was partly dangerous. I think the problem was that he didn't have the full range of what was needed. You know we thought he was the man for the job, we 
did think he was the person for the job because he said all the right things and so on, but actually he didn't seem to be able to manage it. He let the right-wing get power and didn't seem to be able to manage them out. And when he resigned I remember being absolutely devastated because I remember thinking he was the last kind of last bastion against them, but I didn't have any faith in him really. So it was, you know, 'well now we're really lost. This is a disaster', and I could see 1990 coming...

('Jane', trade union representative).

Here, David Lange is further cast as a Man Alone in the Labour Party, and positioned as the only actor who could have prevented the right-wing takeover of New Zealand's Labour Party. The assertion and evaluation of Lange as being 'the last kind of bastion against them' is indicative of Lange's maintained place in the collective memory of participants as a symbol of Labour and socially progressive ideals, even as right-wing structural adjustments were implemented by the Party he led. A trade union representative echoed the collective sense of defeat expressed by participants and the realisation of the complete takeover of the Labour Party by right-wing reformers,

I don't recall exactly what year it was, but it must have been in the '87-'90 period, possibly ' 87 or ' 88 and Roger Douglas gave a speech about the flat tax and why it was important to have a flat tax rate, because we had people who - high earners who were disincentivised by a high tax, progressive regimes, who would leave the country and go and we'd lose their talents and all this sort of thing if they go, if they have to pay the sort of tax rates that were being demanded at that time. And so we had to have a flat tax regime, which of course was a big conflict in that period. And of course at the end of his speech, I asked an innocent question, well it wasn't really innocent, from the audience; I asked him, and during this time I'd actually started doing some economics because I thought there was this crap being said and I need to have the language so I can challenge it. So I asked, I said to Roger Douglas 'can you show us the evidence please of this, of the progressive tax regime being a disincentive to these people. Where is the evidence that we're losing talent?' And his response? Was to pick up his papers, slam them on the table [laughs] like that, gather them up again, and walk out of the room... and that was it... yeah... so that was a fairly vivid memory.

('Jane', trade union representative).

Here, the participant, in describing Roger Douglas' call for a flat tax rate - 'a big conflict in that period' - recalls the symbolic end of meaningful and effective debate within the Labour Party and the complete takeover by Roger Douglas and his 'Rogernomics'. In challenging Douglas to provide evidence for his assertion that high earners were disincentivised by progressive tax regimes, the participant recalls in detail the meaning-full response: 'to pick up 
his papers, slam them on the table...gather them up again, and walk out of the room...'. This instance of flashbulb memory, while highly personal, takes on collective significance when the response by Douglas is understood as being symbolic of the uncompromising attitude of the key architect of New Zealand's structural reform, and the finality of the right-wing takeover of New Zealand's Labour Party.

\section{Social drama and the collective arc in narrative}

Tracing the collective narrative arc presented collectively by participants of this study, its rise and fall, and the ongoing significance of this period in their individual and collective memory suggests a process of 'social drama' within the Labour Party and the left more generally. Victor Turner theorised 'social drama' as 'an objectively isolable sequence of social interactions of a conflictive, competitive or agonistic type' (1988: 33). In creating an arc of narrative in the collective memory of participants, we are able to theorise possible social forms and actions isolable stages of the arc may create or fulfil in making sense of collective memory and social breach.

Turner takes a reified view of social drama, conceiving it as a processual, sequential, fullphase structure. For Turner (1987: 4-5), the temporal phases of social drama - A) breach; B) crisis; C) redress and finally; D) either reintegration or the collective recognition of irreparable breach - are preceded by the necessary conditions in which social drama can occur. Key to these conditions are the shared values and interests that together bind the collective in question by a real or perceived common history and identity. This prerequisite is shared by the foundational contingencies of the mnemonic communities described in this study; the social frameworks which give life to a collective sense of memory.

The first of Turner's four sequential phases of social drama is the serious breach of a collective norm or value. This study has outlined the narrative arc of collective memory of both trade union and community and voluntary representatives as following the trajectory of exposition to resolution. Central to this arc is the climax and resulting falling action which in Turner's theory of social drama qualifies as the breach: the election of a Labour government in 1984 that would implement right-wing economic and structural adjustments and have an ongoing impact on New Zealand society and the Labour Party tradition. This breach experienced by participants was collectively recalled as being so severe as to result in Turner's second sequential phase; crisis. Crisis was a word repeatedly used by participants of 
this study. However, its frequency is only apparent during the formative stages of the narrative arc they collectively created through their shared social memory. 'Crisis' was repeatedly expressed in describing the social and economic conditions during both the exposition and rising action stages of the narrative arc in setting the scene for events they evaluated as being climactic, namely the election of David Lange in 1984 and the resulting reforms. It therefore follows, structurally, that crises mentioned during the formative stages of the narrative arc are to be evaluated as less meaningful to the overall arc than crises that occur closer to the climactic stage. The real crisis in the collective memory of participants of this study, that is, the crisis indicative of social breach in the collective arc in narrative, can therefore be found in the realisation and evaluation of the reality of Rogernomics, the impact of structural reform and the tragic departure of the Labour Party from their shared values and sense of identity. Furthermore, this realisation was evaluated by participants as also entailing, in retrospect, the evaluation of a collective departure and shift in values experienced by New Zealand as a whole, as once sacred notions of collectivism and social democratic principles gave way to the neoliberalisation of New Zealand.

The third sequential phase Turner outlines in his theory of social drama is the redress involved in addressing the breach and resulting crisis. Both politically active and inactive participants from both mnemonic communities involved in this study spoke of the relative helplessness experienced by many as Rogernomics and what Jane Kelsey (1995) describes as 'The New Zealand Experiment' were implemented. Redress therefore came in varied, but ultimately limited ways. The most significant collective understanding of redress this study revealed came in the form of limited political and academic resistance, the eventual ousting of several key architects of Rogernomics from the Labour Party, and the introduction of MMP (Mixed Member Proportional representation) in 1994. Finally, Turner's fourth and final sequential phase of social drama involves either the reintegration of the disrupted social group or the collective recognition of the breach as irreparable. To this final phase, the collective memory and narrative arc of participants of this study lead us to the ongoing work of resolution/denouement in the collective narrative. 


\section{$7 \quad$ Resolution/denouement: Social schism and partial reintegration of breach in New Zealand's Labour tradition}

Understanding the narrative arc of the collective memory of participants of this study as following the sequential and isolable structure of social drama outlined by Turner (1987) allows for the resolution/denouement stage of the arc to be treated as necessitating either reintegration or social schism. Turner (1987: 5) describes this final stage of social drama as consisting of either 'the reintegration of the disturbed social group, or of the social recognition and legitimation of irreparable schism between the contesting parties'. Turnerian theory sees reintegration as entailing resolution within the social group, albeit with altered relations and systems of meaning, while social recognition of irreparable breach is likely to involve the voluntary separation of certain elements or parties within the group (Turner, 1982). For the purposes of this study, the preferred term social schism will replace 'social recognition', as it better describes the collective response encountered in this research to the sense of betrayal experienced within New Zealand's Labour Party. Using this final stage in the theory of social drama allows for an interpretation of the resolution/denouement stage in the narrative arc of collective memory which once again places the collective memory of participants in the ideological and organisational concerns of the present. Furthermore, the resolution/dénouement stage of the collective narrative arc can be understood as consisting of both reintegration and social schism, as participants described the immediate fallout of the collective realisation of structural adjustment, and a perceived revitalisation of hope for the future of the Left in New Zealand.

As discussed in the previous chapter, the falling action of the arc in the collective narrative of the past presented by participants consisted of the collective realisation of right-wing structural adjustment by New Zealand's traditionally social-democratic Labour Party, and the associated sense of shock and betrayal that came with this shift within the Labour tradition. Redress was found in a number of ways, according to participants; however, establishing both reintegration and social schism required a period of evaluative memory-work on the part of participants in creating a collective sense of resolution. Participants again provided highly emotive details as they sought to attach meaning to the events of this period. Where this stage of resolution differs from previous stages of the collective narrative arc is that greater meaning and significance can be found in the emotions of participants, rather than the highly materially-textured accounts indicative of flashbulb memory. While this research 
follows a tradition of understanding flashbulb memories as being contingent on high levels of emotional arousal, within resolution/denouement, it is any many cases the emotions themselves and the evaluative process that takes on meaning, without necessarily the event or material action acting as a vehicle of translation. Where the memory of events and more emotive evaluations merge is in establishing the past as integral to the present organisational and ideological needs and concerns of participants.

\section{The silence of change}

For those participants who were not 'politically active' or formally aligned to the Labour Party, personal memories took on shared significance as they described the detachment many felt from economic structural adjustments which had little immediate impact on their day-today lives. There was therefore an element of indifference evident in the recollections of the politically 'inactive' participants as they evaluated the immediate impact of reforms.

Colin James (1986) described New Zealand's neoliberal structural adjustments following 1984 as 'the quiet revolution'. While reforms were implemented fast, often without warning and at an unprecedented scale for a Western democracy, reference to this period as 'the quiet revolution' was echoed by all participants of this study in their collective memory of the more immediate changes evident in New Zealand. A community and voluntary representative described his personal experience of this period:

I was 27 years old, I'd been unemployed or working part time for that long, it didn't impact me. I mean, what change did that have on me? I was still unemployed, or on work schemes. You know? For me that was the reality. And my way of looking at it, was that this was something about the 'fat-cats'. This was a fat-cat thing, not a thing about me. So we weren't really politicised at all at that time. So I was part of the generation of young people who didn't see politics as being part of their world...

A closer reading of this excerpt reveals a turn from the singular pronoun ' $\mathrm{I}$ ', to the plural pronoun 'we' in representing the collective memory of this participant's community at the time of structural adjustment. The interviewee continues in positioning memories of this period in the needs and concerns of the present as a part of the community and voluntary mnemonic community:

We didn't think about the politics of it. We thought more about the... basically the survival of it. We were involved in that whole social enterprise; the black economy was really strong... just about everybody tried to have an 'under-the-table' job. If you 
could get an under-the-table job and still be on the benefit and didn't declare it, you didn't pay tax on it...

...There was a lot of that going on, so it was... so anytime someone could get a job like that, whether it was chopping wood, or whatever it might be, that you could produce a little bit of extra income for your family, you did it. That was almost part of the driver to the position we are in today, because people were going, 'oh look at those people, they're on the dole ${ }^{17}$, they don't want to go off the dole'. Well, they're on the dole and they've figured out, well, if they do a bit of work chopping firewood or doing this and that and selling that, they can actually create a sustainable lifestyle...

...And so people were working really hard at creating a sustainable lifestyle where employment was really difficult to get and often unsustainable. And the government was thinking, 'well, we're going to do something about that', and that led to much harsher benefit regimes and a public perception that people wanted to be on the dole, whereas actually it was a response to the situation at the time. You know? But that kind of concept, 'oh they're on the benefit, they're doing better than we are' led to acceptance of the $20 \%$ cuts, and suddenly it became much harsher to be on the dole. That 20\% cut in benefits led to, 'well if you can get a job, you can get a better income', and then that led to, 'well, why do we have to pay so much in wages when people are cuing up for jobs?'...

('James', community and voluntary representative).

Here the participant moves temporally through the structural adjustments beginning in 1984, through to the continuation and acceleration of neoliberal adjustments by the National Party which succeeded the Fourth Labour government in 1990, before placing the account within the present needs of the community and voluntary sector, with their focus on family and community. While details and subsequent events are related, meaning here resides in emotive use of the word 'survival' and the instrumental use of memory in establishing the ongoing impact on the community and voluntary sector. In the use of time, the participant creates a causal link between the reforms beginning in 1984 and the focus on personal responsibility indicative of today's neoliberalism, which has an ongoing impact on the work of the community and voluntary sector. A revisit and extension of this participant's metaphor of the 'ground shifting' is helpful here in summarising the collective memory of change experienced by those participants who were politically inactive during this period,

There were big social movements, but less understanding of the ground shifting. So the ground was shifting on you, without you even really understanding or knowing it. The kind of way society was structured was shifting, without you really understanding

\footnotetext{
${ }^{17}$ Unemployment benefits.
} 
that that was what was happening. So for me that period was one where the impacts on people was kind of obvious. What to do about it was you responded practically to try to achieve some practical result without understanding that there was perhaps a greater political shift that you needed to be addressing.

('James', community and voluntary representative).

Here again, a shared sense of cultural disorientation is expressed as resulting from profound changes that were difficult to detect in their immediate impact, but which continue to this day. This metaphor of 'the ground shifting' is indicative takes on collective significance as it describes collective reality, and a period of significant change in New Zealand's history, within the Labour Party, and within New Zealand's political Left.

\section{Social schism meets instrumental reintegration}

For those participants who were politically active at the time of New Zealand's structural adjustments, the realisation of neoliberal reform and the betrayal of the Labour tradition was evaluated and resolved in a significantly more instrumental manner. Again, during this resolution/dénouement stage of the narrative arc, participants placed collective memory of this period in terms of present organisational and ideological needs and concerns. Prior to doing so, participants continued in emotionally meaningful evaluative work in describing highly personal, yet collectively-held reactions to this realisation. A trade union representative recalled the personal and collective challenges posed by the betrayal of the Labour Party tradition:

Well, I've been thinking about it a lot lately, but yes that was really important, it was... it was hard. That's how I recall it. I recall it as being an extremely challenging time about 'where do I stand, and how do I get what I want to happen? And I'm kind of stuck, you know?' And feeling like the power was slipping away, whereas there had been a feeling of actually being able to influence things through the Labour Party up until then.

\section{('Jane', trade union representative).}

Rhetorically asking 'where do I stand, and how do I get what I want to happen?' and feeling 'stuck' is here indicative of a collective sense of cultural disorientation experienced by politically active participants of this study which, together with a Turnerian understanding of social drama, necessitates acknowledgement of either reintegration or social schism in the collective memory-work of participants. This collective sentiment was echoed by a fellow 
trade union representative who would disavow the Labour Party in favour of Jim Anderton's Alliance Party, in highly emotive terms:

I used to come to Labour Party conferences as a young person and we felt like one family, we all spoke the same stuff, until such time as we had Roger Douglas, and then it disintegrated widely...

... [My] heart had left the Labour Party. I honestly felt like someone had put a spear through my heart that the Labour Party... I have never regained that passion for the Labour Party. It will never come back. It would take a month of Sundays...

.... So it was quite powerful at the time. I remember thinking 'I've got to leave the Labour Party', so I did. As soon as Jim [Anderton] set up the Alliance ${ }^{18}$, I remember sending Jim a post card from -I had gone to Australia for my first ever trip - I sent him the red rock from Ayers Rock - and saying 'I'm part of the Alliance'; I think I was a foundation member. 'Join me up. I can't stand it anymore!' You know? So definitely with people from the Left, there was a huge outpour of grief really, about what happened to the Labour Party, and I don't think I ever felt strongly connected to them again, even though I try build relations with them, I don't think I really trust them.

But they continued the march didn't they, and seriously, and didn't provide any safety from that for the people in our country, that's how I feel. They shafted us.

('Karen', trade union representative).

The collective sense of betrayal expressed by participants is telling of a profanation and polluting of sacred and pure ideals within the Labour Party tradition. The social breach described by Turner in his theory of social drama, and here understood as the climax in the narrative arc of collective memory, takes on collective and symbolic significance when it is understood as a profanation of the sacred, and a polluting of the pure. Still, for several participants, there was a collective sense that the Labour Party could not be abandoned, expressed here by a trade union representative:

One of the real problems that you had was that in the Party people like myself and quite a number of us, stuck with the Party because we had seen what happens in Australia when you leave the main social democratic party; that basically you get buried. It just peters-out because it doesn't have a mass, popular base. We were fortunate because we all stayed and the Andertonites left, and we forced the Douglasites out, and we were left with a sort of centre-Left, and centre-Right group around Helen [Clark] and we were able to rebuild it and get rid of the worst excesses of it. So I think if you look back, there was a real sense of betrayal in the Labour

\footnotetext{
${ }^{18}$ Formed in 1991 as an alliance of four political parties: the NewLabour Party, the Democratic Party, Mana Motuhake, and the Green Party. The party formed in opposition to Rogernomics and Labour's structural adjustment and represented left-wing economics, Māori issues, and environmentalism. The Party deregistered in 2015 .
} 
Party, there was a lot of sort of personal...people's worlds were shot to death with redundancies, and I think it was a very brutal form of structural readjustment, that left a lot of people as casualties, and then a group basically captured the surplus value of state assets. It was a very unpleasant period. Very stressful period for everyone involved, and a lot of people lost jobs, and there were people who never really managed to recover their lives again.

('Bill', trade union representative).

Here, we encounter a divide in subjective experience within the collective memory of participants in terms of individual responses to structural adjustments and the betrayal of the Labour Party tradition. While some participants left the party completely, following a fracturing of the Left in response to the take-over of neoliberal ideals, others remained as a means of ensuring any remaining core principles of the Labour Party were salvaged and protected. This deviation in the details of narrative can be understood as social schism on the part of those who left, and instrumental reintegration on the part of those who chose to stay with the Labour Party. For those who remained, resolution and instrumental reintegration was described in terms of a 'call for a return to the past' and the ousting of several of the key architects of Rogernomics, as described here by a trade union representative:

Where was this call for a return to the past? It was a feeling. And again in the union debate, there was a lot of people who had always belonged to the Labour Party and had abandoned it. So that saw the birth of NewLabour and other left-wing parties and those closer to the party saw that we actually needed to ditch the Prebbles, the Roger Douglas' and cohorts, and shift away, and in some respects I think that's why Lange came away in the end. It wasn't the party that he was a part of.

('Adam', trade union representative).

Here, the participant recalls the collective feeling within Labour that the Party's traditional ideals had been severely jeopardised, or lost completely, and that in order for the collective to return to their position on the left of the political spectrum, and closer to their sacred ideals, the architects of right-wing structural adjustment would need to be isolated and removed from the Party. In doing so, the Labour Party was able to path the way for Helen Clark, the Fifth Labour government's Prime Minister in 1999.

\section{The partial reintegration of the Labour Party}

In the collective memory of participants of this study, 1999 and the Fifth Labour government's Helen Clark offered a form of partial reintegration of the Labour Party, the 
Left and of New Zealand's grand narrative of social progress. A trade union representative's recollection of this period was indicative of a collective narrative of rejuvenated hope, a perceived partial-return to the Party's sacred ideals, and the collective memory of this period as being experienced as a return to a more hopeful New Zealand:

Yes, it was exciting. And interestingly, I remember that again from the ' $90 \mathrm{s.}$ I mentioned this to some colleagues, you know, it turns. Things do get better again. They go bad and they get better again. The '90s were a period... well the '90s started it, but more in to the 2000s. The 2000s when Labour was in power, it started to get better, it started to feel more like 'my New Zealand society' again. It started to. It didn't ever get there completely though because the neoliberal stuff was still there; it had never really gone. The language was still there and the ways of thinking were still there. But there were good things happening as well, it balanced it a bit. And I remember my older daughter came home from England in the early 2000s, or maybe the mid-2000s, coming back for a visit and saying 'mum, this is a completely different country from the one I left', because she left at the end of the '90s. Labour came in in 1999 again and she [daughter] left by the time they came in, but there was all that stuff that Helen [Clark] was doing about the arts, and there were all sorts of exciting things happening, and there was... it felt to me like a more hopeful place...

This excerpt of narrative is indicative of a sense of partial reintegration expressed collectively by participants in recalling Helen Clark and the Fifth Labour government in the resolution/denouement stage of the collective narrative arc. Evidence of merely a partial reintegration of the Labour Party, the Left and of a partial return to the sacred ideals of collectivism and social democratic principles is established through the assertion that this return had only 'started' and that 'It didn't ever get there completely... because the neoliberal stuff was still there'. The evaluation that this partial reintegration 'balanced it a bit' implies a centring of the Left in New Zealand's political landscape. The participant continued in explaining her evaluation that 'it started to feel like 'my New Zealand society again"':

... I'm thinking of a New Zealand... I mean, part of it is mythical really. A New Zealand that is accepting of diversity, which probably is mythical because it's only certain types of diversity that were accepted in the past. It depends how far back you go. Perhaps if you were thinking back to the '70s, it was still a struggle, but at least there was a feeling you might win. But... one where equality, no, equity was important... Ahhh... I don't know actually...

...oh, it was also... some of it was new really. I remember sitting on a tram in Melbourne and chatting with an elderly woman, an Australian who said - it was during the time that Helen [Clark] was Prime Minister - and she said 'you've got a woman PM in New Zealand? That's amazing'. And me saying 'well we don't just have a woman Prime Minister, we also have a Chief Justice, and we have... there 
must have been a time when we had a Governor General too... Anyway, I said 'well we've got women in three of the most important roles'. And I think we had Theresa Gattung leading Telecom at the time as well. We had women everywhere. We don't have that now. There's been a sense of there being a real male takeover again.

('Jane', trade union representative).

The excerpt traces a path through time, instrumentally implementing a form of mnemonic rhyming in describing a mythologised past, with the Fifth Labour government's time in power. The participant describes a pre-1984 New Zealand in which 'equity was important' and in doing so implies that the Fifth Labour government's New Zealand was a time when these values had been partially regained. Again, a caveat is offered in the statement that this idealised New Zealand was perhaps only mythical, and that 'only certain types of diversity were accepted in the past', before implying a return to the New Zealand's grand narrative of social progress in describing three women in positions of power, symbolised by Helen Clark herself as Prime Minister. The excerpt closes by returning the narrative to the present and the participant's evaluation of there being a 'sense of there being a real male takeover again' which coincides with the dominance of New Zealand's Fifth National government in power since 2008 .

\section{4 as an unassimilable breach}

Ultimately, a maximal interpretation and collective understanding of this resolution/denouement phase of the collective arc in narrative - asserting both social schism and partial reintegration - sees resolution by participants as entailing the acknowledgement of a breach yet to be repaired. In the collective narrative of participants, the structural adjustments beginning in 1984 and the right-wing takeover of New Zealand's Labour Party therefore constitute what Jeffrey Olick refers to as an 'unassimilable breach'(1999: 345).

While the instrumental reintegration of the Labour Party and the resulting partial reintegration of the Party's core values, exemplified by the Fifth Labour government, represent a centring of the Left in New Zealand, the neoliberalisation of New Zealand's social, economic, cultural and political landscape has continued through successive governments, from both ends of the political spectrum. In the collective memory of participants, coda, or the summation of collective narrative, was located in equating the ongoing work of recovery within New Zealand's Left, with present and future organisational, 
ideological and global needs and concerns. Speaking of the structural adjustments and the neoliberalisation of New Zealand, a community and voluntary representative reflected on funding structures in the public sector and the commercialisation of welfare provision experienced within the community and voluntary sector:

I don't think its been for the best at all really. I think we have a fractured society in many respects. I don't think society cares for itself enough. I think that's kind of evident still in the way the state funds important areas of the public sector, like health, education, the notion that in health there's community support, you know, relying on the Salvation Army, and these community groups stepping in, and given a bit of funding to help...

('Judy', community and voluntary representative).

Here the participant evaluates the ongoing impact of Rogernomics and neoilberalism on society. The assertion that 'we have a fractured society' implies a loss of the kind of collectivism and sense of solidarity crucial to the work of both community and voluntary and trade union representatives, and positioned equated, in the collective memory of participants with Keynesian, social democratic New Zealand. Similarly, a trade union representative described the prevalence of individualism as it relates to employment:

If you think about the reforms to promote the individual as a strategy to enable that right-wing agenda to be set in place, then it worked. Where it might be starting to get a bit frayed is around the edges because we saw high unemployment. It's interesting, there's now been some actions taken against 'zero hour' contracts, and some of that has gained traction in the media. I remember saying once that it would take five minutes to destroy the country through this particular agenda, and it will probably take three generations to restore it. It's a long process. And people have become.... they know no different. They've been born into it...

('Adam', trade union representative).

The participant continued with his assessment of the encroachment of neoliberal ideas and the resulting culture-shift experienced in New Zealand:

It's all based on individualism. I think there was more community spirit. Now it's all value, the value of money. Commoditised, I think, and trying to, I think there's even less involvement in the politics, because they've been able to get people to...the trick of the right, I think, has been to make wealthy people think they're men of the people like [John] Key ${ }^{19}$, which is absolute bullshit. Marx said religion was the opiate of the people, well...consumerism, and entertainment, and celebrity is the new opiate of the

\footnotetext{
${ }^{19}$ Prime Minister and leader of the Fifth National government of New Zealand since 2008 at the time of publication.
} 
people. There's such mystification of society now, and it really operates in encouraging people to be individual and not stand up for themselves and not think about life and what the real base of it is.

('Bill', trade union representative).

Here, a direct link is made between organisational and ideological needs and concerns which sees the individualism, commoditisation and consumerism indicative of neoliberalism linked to a collective sense by participants that these neoliberal attributes have negatively impacted 'community spirit'. This perceived deficit can be understood as impacting on the core principles and objectives of both the trade union and community and voluntary mnemonic groups, but also constructed sacred notions within New Zealand's idealised grand narrative. Participant's coupled this evaluation of the colonisation of social democracy by neoliberal ideals, with an overt sense of hope for the future, exemplified here in the sentiment of a trade union representative:

I'm an optimist. I kind of hope that people will get it. I hope that political forces will eventually come to bear. My judgement is that political parties won't stray too far from the centre. So there's a line, if you want the popular vote, which is a pity, because you won't get that significant shift. So I'm not predicting a significant shift any time soon ... but I think it's just a matter of when.

('Adam', trade union representative).

References to Helen Clark and the Fifth Labour government, and the above assertion that a 'significant shift' akin to that experienced as a result of structural reforms beginning in 1984, suggests a cyclical understanding of the changing political landscape, and perhaps of history itself. With the global spread of neoliberalism under increasing scrutiny, participants of this study resolved their collective memory of structural adjustment and the betrayal of New Zealand's Labour tradition, with an eye to the future of both domestic and global concerns and with hope for the global Left. 


\section{Concluding comments}

In developing an understanding of the shared, collective memory of community and voluntary and trade union mnemonic communities, this study has traced a collective arc of narrative presented by participants. Gathered through individual interviews with ten participants, the collective memory presented here follows the five sequential phases of a narrative arc: exposition, or the introduction in which characters are introduced and the setting is established; rising action, a series of complicating events which create tension; climax, the turning point or the point of greatest tension; falling action, or the unfolding of events, and finally; denouement/resolution, or the outcome that concludes the narrative arc and offers clarity and explanation. In keeping with this understanding of the sequential structure of narrative arc, this research identified the exposition in Chapter (3: Part I) presented by participants as the largely historical memory offered by interviewees in describing key political actors involved in structural adjustment beginning in 1984. Here, mnemonic framing (Chapter 3: Part II) utilised by participants was also crucial in providing context for both the collective memory presented, but also how this memory is framed with regard to the present concerns of the mnemonic community in question.

A thematic analysis of interview material found that community and voluntary representatives collectively framed their memory of this period in terms of the impact on families of structural adjustments and the continued neoliberalisation of New Zealand. An organisational and presentist understanding of collective memory places this focus on the family firmly within the present needs and concerns of the community and voluntary sector. Similarly, in the collective memory of trade union representatives, memory of this period was frequently framed with regard to employment and employment relations. This research found commonality between the two mnemonic communities in the framing of memory around issues related to community. The concept of mnemonic framing was presented in this study to provide context for the arc of narrative which would follow. While much of the narrative that sought to frame collective memory of structural adjustment in New Zealand centred on historical memory which was highly group-specific in relating to organisational needs and concerns, the collective narrative which followed entailed a higher frequency of autobiographical memory which took on shared, collective significance.

Continuing this arc of narrative, Chapter (4) examined the stage of rising action which consisted of collective memory of social change and historical density in New Zealand during 
the 1970s and early 1980s. This period in New Zealand's history was experienced collectively by participants as being fraught with tension, conflict and drama, socially, politically and economically, and giving rise to a new political consciousness following the Springbok tour of New Zealand in 1981.

Chapter (5) sees this rising action continue. Amidst social and economic crises, a new political consciousness began to increasingly question hegemonic and Establishment-New Zealand, symbolically represented by then Prime Minster Robert Muldoon and the socially conservative and traditionalist National Party. A maximal interpretation and cultural sociological analysis of the collective memory of participants positioned David Lange alongside the sacred and pure Leftist ideals of change, progress and social individualism, and associated Muldoon with the profane and polluted discourse of stagnation and social conservatism, within New Zealand's overarching grand narrative of progress and egalitarianism. This rising action reached its climax with David Lange and the Fourth Labour government winning the 1984 general election. In equating himself with the sacred and pure along this binary discourse, Lange successfully won the 1984 election amidst a prevailing sense of hope for change, economic recovery and social progress.

Chapter (6) follows the collective arc of narrative apparent in the collective memory of participants from climax into the stage of falling action. Here, the realisation of structural adjustment, of the neoliberalisation of New Zealand and the betrayal of the Labour Party tradition is conveyed by participants in highly personal and emotional instances of flashbulb memory. A maximal interpretation of this realisation sees the structural adjustments beginning in 1984 as heralding in a cultural shift in New Zealand's social, economic, cultural and political landscape that continues to impact the broader New Zealand collective.

The four stages of the collective narrative arc - exposition, rising action, climax and falling action - were then described in terms of social drama. In doing so, Chapter (7), in which the narrative arc moves to resolution/denouement, can be understood - in the tradition of social drama - as requiring either reintegration, or the social recognition of the breach as irreparable, here termed social schism. The breach in question is revealed in the collective memory of participant's as the takeover of the Labour Party by right-wing reformers and the structural adjustments that followed. This study found evidence in the collective memory of participants of both social schism in the fracturing of New Zealand's Left, and partial reintegration in the centring of the Left which culminated in the rise of Helen Clark and the 
Fifth Labour government. This research therefore concludes that the suggestion of both social schism and reintegration in resolving social breach entails the evaluation of the Labour Party and the Left as in a state of ongoing repair.

The Labour Government of 1984-1990 was responsible for the creation and application of a dramatic shift in the shape and form of New Zealand society. In tracing a path following the collective arc in narrative of participants, we can better understand how this radical and unexpected social, cultural and political shift was, and continues to be experienced.

Collective memory is ongoing, social and constructive. While all participants differed in the autobiographical details of their memory of structural adjustments and the deviation of the Labour Party its social democratic tradition; understood collectively, highly personal details which constitute instances of flashbulb memory are shown to take on shared significance between participants of this study. Further maximal interpretation of the collective memory of interviewees reveals how in successfully positioning David Lange and New Zealand's Labour Party within a sacred and pure discourse, the profanation and pollution of a sense of collectivism and of the Labour Party tradition became pronounced, leading to a schism in the Left which remains to this day.

The inherent intersubjectivity of collective memory reveals how highly personal memories collectively represent a prevailing sense of shock and dismay at the course of events associated with radical structural adjustment. These collective emotions find saliency as they are attached to material circumstances in the form of flashbulb memories which continue to shape the politics and larger collective memory of those on New Zealand's political-Left.

The Fourth Labour government's adoption and implementation of neoliberal ideals constitutes an unassimilable breach in the collective memory of participants. In order for there to be social and cultural repair within the Labour Party and the Left more broadly, and for New Zealand's civil discourse to return in proximity to its once sacred emphasis on social progress and the collective, the present must be understood as in constant negotiation with the past. Coming to terms with, and understanding this connection is key to understanding our future. 


\section{Bibliography}

Alexander, J. (2011). Market as narrative and character: For a cultural sociology of economic life. Journal of Cultural Economy, 4(4). Pp. 477-488.

Alexander, J. (2010). Heroes, presidents and politics. Contexts, 9(4). Pp. 17-21.

Alexander, J. (2009). The democratic struggle for power: the 2008 presidential campaign in the USA. Journal of Power, 2(1). Pp. 65-68.

Alexander, J.C. (2007). The meaningful construction of inequality and the struggles against it: A 'strong program' approach to how social boundaries change. Cultural Sociology, 1. Pp. 23-30.

Alexander, J.C. (2006). The Civil Sphere. New York: Oxford University Press.

Alexander, J.C. (2004). Toward a Theory of Cultural Trauma. J.C. Alexander, R. Eyerman,

B. Giesen, N. J. Smelser, P. Stzompka. Cultural Trauma and Collective Identity. (Pp. 1-30). Berkley: University of California Press.

Alexander, J. C., Eyerman, R., Giesen, B., Smelser, N. J., \& Sztompka, P. (2004a). Cultural trauma and collective identity. Berkeley: University of California Press.

Alexander, J.C. (2003). The Meanings of Social Life: A Cultural Sociology. New York: Oxford University Press.

Alexander, J.C. \& Smith, P. (2003). The strong program in cultural sociology: Elements of a structural hermeneutics. In J. Alexander (Ed.), The Meanings of Social Life. Oxford: Oxford University Press.

Alexander, J. \& Smith, P. (1993). The discourse of American civil society: A new proposal for cultural studies. Theory and Society, 22(2). Pp. 151-207.

Armstrong, E. Crage, S. (2006). Movements and memory: The making of the stonewall myth. American Sociological Review, 71(5). Pp. 724-751.

Autor, D. Katz, L. \& Kearney, M. (2006). The polarisation of the US labour Market. American Economic Review, 96(2). Pp. 189-194. 
Ayerman, R. (2004). Slavery and the formation of African American identity. In J.C Alexander (Ed.), Cultural Trauma and Collective Identity (pp. 60-111). Berkely, California: University of California Press.

Bamfield, L. \& Horton, T. (2009). Understanding attitudes to tackling economic inequality. York: Joseph Rowntree Foundation.

Bannister, M. (2005). Kiwi blokes: Recontextualising New Zealand Masculinities in a Global Setting. Genders, 42. Pp. 1-25. Retrieved from:

http://researcharchive.wintec.ac.nz/217/1/kiwi_blokes.pdf

Bartels, L. (2008). Unequal Democracy: The Political Economy of the New Gilded Age. Princeton: Princeton University Press.

Bartels, L. (2005). Homer gets a tax cut: inequality and public policy in the American mind. Perspectives on Politics 3(1). Pp. 15-31.

Bodnar, J. (1989. Power and memory in oral history: Workers and managers at Studebaker. Journal of American History, 75(4). Pp. 1201-1221.

Bodnar, J. (1992). Remaking America: Public Memory, Commemoration, and Patriotism in the Twentieth Century. Princeton: Princeton University Press.

Boston, J. Eichbaum, C. (2014). New Zealand's neoliberal reforms: Half a revolution. Governance: An International Journal of Policy, Administration, and Institutions, 27(3). Pp. 373-376.

Bourdieu, P. (1998). The Essence of Neoliberalism. Le Monde Diplomatique. March. Retrieved from: http://www.monde-diplomatique.fr/1998/03/BOURDIEU/10167

Brown, R. \& Kulik, J. (1977). Flashbulb memories. Cognition, 5. Pp. 73-99.

Butler, T. (1989). Memory. New York: Basil Blackwell.

Carr, D. (1991). Time, Narrative and History. Bloomington: Indiana University Press.

Centre for Labour and Social Studies. (2013). Exposing the Myths of Welfare. London: Centre for Labour and Social Studies.

Coleman, P. (1982). New Zealand liberalism and the origins of the American welfare state. The Journal of American History, 69(2). Pp. 372-391. 
Converse, P. (1964). The Nature of Belief Systems in Mass Publics. In D. Apter (Ed.), Ideology and Discontent (Pp. 206-261). New York: The Free Press.

Connelly, T. (1977). The Marble Man: Robert E. Lee and His Image in American Society. New York: Khopf.

Connerton, P. (1989). How Societies Remember. Cambridge: Cambridge University Press. Chomsky, N. (1999). Profit over People - Neoliberalism and Global Order. New York: Seven Stories Press.

Coontz, S. (1992). The Way We Were. New York: Basic Books. Crage, S. (2008). Negotiating the relevance of the past: refugee aid and policymaking in Berlin. Paper presented at the annual meeting of the American Sociological Association; Boston, Massachusetts.

Crawford, S. (1988). Rugby in contemporary New Zealand. Journal of Sport and Social Issues, 12(2). Pp. 108-121.

Davies, W. (2014). Neoliberalsim: A bibliographic Review. Theory, Culture \& Society, 31(7/8). Pp. 309-317.

Dean, J. (2008). Enjoying neoliberalism. Cultural Politics, 4(1). Pp. 47-72.

Dean, M. (2012). Rethinking neoliberalism. Journal of Sociology, 50(2). Pp. 1-14.

Debs, M. (2004). The suffering of symbols: Giotto frescoes and the cultural trauma of objects. Cultural Sociology, 7(4). Pp. 479-494.

DeGloma, T. (2015). The strategies of mnemonic battle: On the alignment of autobiographical and collective memories in conflicts over the past. American Journal of Cultural Sociology, 3(1). Pp. 156-190.

De Kruijif, J \& Toppen, A. (2014). Dollars and delusion: Global finance, cultural trauma and ethno-economic subjectivity in post-boom Iceland. Journal of Contemporary European Studies, 22(4). Pp. 377-394.

Denzin, N. (2001). Interpretive Interactionism (2nd edition). Thousand Oaks, California: Sage. 
Dinitto, R. (2014). Narrating the cultural trauma of 3/11: the debris of post-Fukushima literature and film. Japan Forum, 26(3). Pp. 340-360.

Douglas, R. (1980). There's Got to be a Better Way! A practical ABC to solving New Zealand's major problems. Wellington, New Zealand: Fourth Estate Books.

Ducharme, L. Fine, G. (1995). The construction of demonisation and nonpersonhood: Constructing the 'traitorous' reputation of Benedict Arnold. Social Forces, 73. Pp. 13091331.

Durkheim, E. (1976). The Elementary Forms of the Religious Life. London: Allen and Unwin.

Easton, B. (2013). Economic Inequality in New Zealand: A User's Guide. New Zealand Sociology, 28(3). Pp. 19-66.

Easton, B. (1997). In Stormy Seas: The Post-War New Zealand Economy. Dunedin, New Zealand: Otago University Press. Retrieved from: http://www.eastonbh.ac.nz/1997/11/the_relevance_of_rogernomics/ Easton, B. (1997a). A permanent revolution? Zealots and common sense. New Zealand Studies, July. Pp. 30-36.

Easton, B. (1996). Of dogma and dealers. Electronic Journal of Radical Organisational Theory, 27(3). Retrieved from: http://www.mngt.waikato.ac.nz/ejrot/vol2_1/easton.pdf Easton, B. (1994). How did the health reforms blitzkrieg fail? Political Science, 7(5). Pp. 4773.

Edwards, B. (2010). Why economic inequality doesn't matter: the politics of inequality in New Zealand. Why Economic Inequality Matters Conference: University of Otago.

Edwards, B. (2008). Political finance and inequality in New Zealand. New Zealand Sociology, 23(2). Pp. 4-17.

Edy, J. (2006). Troubled Pasts. Philadelphia: Temple University Press.

Ekstein, M. (1993). Rites of spring: The Great War and the Birth of the Modern Age. Boston: Houghton Mifflin Company.

Erikson, K. (1994). A New Species of Trouble. New York: W.W. Norton \& Company. 
Evans, P. (1990). Introduction. In J. Mulgan, Man Alone. Auckland, New Zealand: Penguin Books.

Fenton, S. (1984). Durkheim and Modern Sociology. Cambridge: Cambridge University Press.

Flew, T. (2014). Six theories of neoliberalism. Thesis Eleven, 122(1). Pp 49-71.

Fogo, F. (1990). "Come together, over me”: Generational memory and social drama in the death of John Lennon (Doctorate thesis, The University of Utah). Retrieved from: http://search.proquest.com/docview/303879309/fulltextPDF/A4BCB0D610C941C9PQ/1?acc ountid=14782

Freeman, M. (2014). The hermeneutical aesthetic of thick description. Qualitative Sociology, 20(6). Pp. 827-833.

Friedlander, S. (1992). Probing the Limits of Representation: Nazism and the 'Final Solution'. Cambridge: Harvard University Press.

Fussell, P. (1975). The Great War and Modern Memory. New York: Oxford University Press.

Geertz, C. (1973). The Interpretation of Cultures. New York: Basic Books.

Gregory, S. Lewis, J. (1988). Symbols of collective memory: The social process of memorializing May 4, 1970 at Kent State University. Symbolic Interaction, 11. Pp. 13-233.

Giesen, B. (2004). The trauma of perpetrators: The holocaust as the traumatic reference of German national identity. In J.C Alexander (Ed.), Cultural Trauma and Collective Identity (pp. 112-154). Berkely, California: University of California Press.

Habermas, J. (1993). A kind of settlement of damages: The apologetic tendencies in German history writing, In Forever in the Shadow of Hitler? The Original Documents of the Historikertreit (pp. 34-44). New Jersey: Humanities Press.

Halbwachs, M. (1992). Collective Memory. Chicago: University of Chicago Press.

Halbwach, M. (1952). Les cadres sociaux de la mémoire. Paris, Presses: Universitaires de France.

Halbwachs, M. (1941). La Topographie Legendaire des Evangiles en Sainte Terre. Paris, France: Presses Universitaires de France. 
Hamlin, P. (1982). The Springbok tour of New Zealand. Auckland Law Review, 4(3). Pp. $313-325$.

Hamnett, I. (1984). Durkheim and the Study of Religion. In S. Fenton (Ed.), Durkheim and Modern Sociology (pp. 202-218). Cambridge: Cambridge University Press.

Harvey, D. (2005). A Brief History of Neoliberalism. Oxford: Oxford University Press.

Hobsbawm, E. Ranger, T. (1993). The Invention of Tradition. Cambridge. England:

Cambridge University Press.

Holliday, A. (2007). Doing and Writing Qualitative Research (2nd Edition). Thousand Oaks, California: Sage.

Hughson, J. \& Spaaji, R. (2011). 'You are always on our mind': The Hillsborough tragedy as cultural trauma. Acta Sociologica, 54(3). Pp. 283-295.

Humpage, L. (2008). Radical change or more of the same? Public attitudes towards social citizenship in New Zealand since neoliberal reform. Australian Journal of Social Issues 43(2). Pp. 216-230.

Humphries, M. (1996). The political economy of organisational discourse and control in New Zealand's liberalised economy. Electronic Journal of Radical Organisational Theory, 2(1). Retrieved from: http://www.mngt.waikato.ac.nz/ejrot/vol2_1/humphries.pdf Huyssen, A. (1995). Twilight Memories. New York: Routledge.

Irwin-Zarecka, I. (1994). Frames of Remembrance. New Brunswick: Transaction.

James, C. (1986). The Quiet Revolution. Wellington, New Zealand: Allen and Unwin. Jencks, C. (2002) Does inequality matter? Daedalus, winter. Pp. 49-65.

Jesson, B. Ryan, A. \& Spoonley, P. (1988). Revival of the Right. Auckland, New Zealand: Heinemann Reed.

Jesson, B. (1992). The disintegration of a Labour tradition: New Zealand politics in the 1980s. New Left Review, (1)192. Pp. 37-54.

Jost, J. T. \& Major, B. (2001) Emerging perspectives on the psychology of legitimacy. In J. T. Jost \& B. Major (Eds.), The Psychology of Legitimacy: Emerging Perspectives on 
Ideology, Justice, and Intergroup Relations, (Pp. 3-30). New York: Cambridge University Press.

Kammen, M. (1992). Meadows of Memory: Images of Time and Tradition in American Art and Culture. Austin: University of Texas Press.

Kammen, M. (1991). Mystic Chords of Memory: The Transformation of Tradition in American Culture. New York: Alfred A. Kopf.

Kammen, M. (1978). A Season of Youth. New York: Kopf.

Kelly, P. (1992). The End of Certainty: The Story of the 1980s. Sydney, Allen \& Unwin.

Kelsey, J. (1995). The New Zealand Experiment. Auckland, New Zealand: Auckland University Press.

Koonz, C. (1994). Between Memory and Oblivion: Concentration Camps in German Memory, (Pp. 258-280). In Commemorations: The Politics of National Identity. J. Gillis (Ed). New Jersey: Princeton University Press.

Lamont, M. Swidler, A. (2014). Methodological pluralism and the possibilities and limits of interviewing. Qualitative Sociology, 37. Pp. 153-171.

Lange, D. (1984). Speech given at Western Hutt Electoral Dinner, Tuesday 11 December, 1984.

Lelkes, O. (2009). Attitudes to Inequality. Tarki: European Social Report.

Lewis, B. (1975). History: Remembered, Recovered, Invented. Princeton: Princeton University Press.

Lowenthal, D. (1985). The Past is a Foreign Country. Cambridge: Cambridge University Press.

MacIntyre, A. (1984). After Virtue: A Study in Moral Theory. Notre Dame: University of Notre Dame Press.

Maier, C. (1988). The Unmasterable Past: History, Holocaust, and German National Identity. Camberidge: Harvard University Press.

Maines, D. Noreen \& M. Katovich, M. (1983). The sociological import of G. H. Mead's Theory of the Past. American Sociological Review, 48. Pp. 161-173. 
Muldoon, R. (1984). Election 1984 Campaign - Opening Address, 25 June.

Muldoon, R. (1981). My Way. Wellington: Reed.

Mulgan, J. (1990). Man Alone. Auckland: Penguin Books. (Originally published, 1939).

Neal, A. (1998). National Trauma \& Collective Memory. New York: M.E. Sharpe.

Newman, K. (1993). Declining Fortunes. New York: Basic Books.

Nussbaum, M. (2001). Upheavals of Thought. Cambridge: Cambridge University Press.

O'Brien, M. Wilkes, C. (1993). The Tragedy of the Market. Palmerston North, New Zealand: The Dunmore Press.

OECD. (2011). Divided We Stand: Why Inequality Keeps Rising. OECD Publishing.

Retrieved from: http://www.oecd.org/els/soc/49170768.pdf

OECD. (2008). Growing Unequal? Income distribution and Poverty in OECD Countries.

Retrieved from: http://www.oecd.org/els/soc/41494435.pdf

OECD. (1993; 1994). Economic Surveys: New Zealand. OECD, Paris.

Olick, J. Vinitzky-Seroussi. \& Levy, D. (2011). The Collective Memory Reader. New York: Oxford University Press.

Olick, J. (2006). Products, Processes, and practices: A non-reificatory approach to collective memory. Biblical Theology Bulletin, 36(1). Pp. 5-10.

Olick, J. (1999). Genre memories and memory genres: a dialogical analysis of May 8, 1945 commemorations in the federal republic of Germany. American Sociological Review, 64. Pp. 381-402.

Olick, Jeffrey. (1999a). Collective memory: The two cultures. Sociological Theory, 17(3). Pp. $333-48$.

Olick, J. Robbins, J. (1998). Social memory studies: from collective memory to the historical sociology of mnemonic practices. Annual Review of Sociology, 24. Pp. 105-140.

Olick, J. Levy, D. (1997). Collective Memory and Cultural Constraint: Holocaust Myth and Rationality in German Politics. American Sociological Review, 62. Pp. 921-936. 
Ongley, P. (2014). Work and inequality in neoliberal New Zealand. New Zealand Sociology, 29(3). Pp. 24-29.

Ongley, P. (2013). Work and inequality in neoliberal New Zealand. New Zealand Sociology, 28(3). Pp. 136-163.

Orr. J. (1990). Sharing knowledge, celebrating identity: Community memory in a service culture. In D. Middleton \& D. Edwards (Eds.). Collective Remembering (pp. 169-189). London: Sage.

Ostry, J. Loungani, P. \& Furceri, D. (2016). Neoliberalism: oversold? Finance and Development, June. Pp. 38-41.

Parson, F. (1904). The Story of New Zealand: A History of New Zealand from the Earliest Times to the Present. Philadelphia: C.F. Taylor.

Pelikan, J. (1985). Jesus through the Centuries. New York: Harper and Row.

Pennebaker, J. Banasik, B. (1997). On the creation and maintenance of Collective Memory. In J. Pennebaker, D. Paez \& B. Rime (Eds). Collective Memory of Political Events (Pp. 3-20). New Jersey: Lawrence Erlbaum.

Pennebaker, J. Daez, D. Rime, B. (1997). Collective Memory of Political Events. New Jersey: Lawrence Erlbaum Associates.

Perry, B. (2013). Household incomes in New Zealand: Trends in indicators of inequality and hardship 1982 to 2012. Wellington: Ministry of Social Development.

Persson, T. \& Tabellini, G. (1994) Is inequality harmful for growth? American Economic Review 84(3). Pp. 600-21.

Peterson, M. (1994). Abraham Lincoln in American Memory. New York: Oxford University Press.

Peterson, M. (1960). The Jefferson Image in the American Mind. New York: Oxford University Press.

Plehwe, D. Walpen, B. \& Neunhöffer, G. (2006). Neoliberal Hegemony - A Global Critique. London: Routledge. 
Prager, J. (1998). Presenting the Past: Psychoanalysis and the Sociology of Misremembering. Cambridge: Harvard University Press.

Pickmere, A. (2005, August 14). Obituary: David Russell Lange. The New Zealand Herald. Retrieved from: http://www.nzherald.co.nz/nz/news/article.cfm?c_id=1\&objectid=10340780

Quiggin, J. (1998). Social Democracy and Market Reform in Australia and New Zealand. Oxford Review of Economic Policy, 14(1). Pp. 76-95.

Rashbrooke, M. (2013). Inequality: A New Zealand Crisis - And What we can do about it. Wellington, New Zealand: Bridget Williams Books.

Reardon, J. \& Gray, T. (2007). About turn: An analysis of the causes of the New Zealand Labour Party's adoption of neo-liberal policies 1984-1990. Political Quarterly, 78(3). Pp. 447-455.

Roehm, M. (2015). An exploration of flashbulb memory. Journal of Consumer Psychology, 26(1). Pp. 1-16.

Rose, N. (2006). The death of the social? Re-figuring the territory of government. Economy and Society, 25(3). Pp. 327-356.

Rosenzweig, R. \& Thelen, D. (1998). The Presence of the Past: Popular Uses of History in American Life. New York: Basic Books.

Rothstein, B. \& Uslaner, E. M. (2005). All for all: Equality, corruption, and social trust. World Politics, 58(1). Pp. 41-72.

Rousso, H. (1991). The Vichy Syndrome: History and Memory in France since 1944.

Cambridge: Harvard University Press.

Russell, N. (2006). Collective memory before and after Halbwachs. The French Review, 79(4). Pp. 792-804.

Saad-Filho, A. \& Johnston, D. (2005). "Introduction" in A. SaadFilho and D. Johnston (Eds.) Neoliberalism - A Critical Reader. London: Pluto Press.

Schudson, M. (1993). Watergate in American Memory. New York: Basic Books.

Schudson, M. (1992). Watergate in American Memory: How We Remember, Forget and Reconstruct the Past. New York: Basic Books. 
Schuman, H. Corning, A. (2012). Generational memory and the critical period: Evidence for national and world events. Public Opinion Quarterly, 76(1). Pp. 1-31.

Schuman, H. Corning, A. (1999). Collective Knowledge: Nine Soviet Events from the Great Purge to Glasnost. American Journal of Sociology.

Schuman, H. Belli, R. Bischoping, K. (1997). The Generational Basis of Historical Knowledge. In D. Paez \& B. Rime (Eds.), Collective Memory of Political Events: Social Psychological Perspectives (Pp. 47-77). Erlbaum Associates.

Schuman, H. Rieger, C. (1992). Historical analogies, generational effects, and attitudes toward war. American Sociological Review, 57. Pp. 315-326.

Schuman, H. Scott, J. (1989). Generations and collective memory. American Sociological Review, 54. Pp. 359.

Schwartz, B. (2000). Abraham Lincoln and the Forge of National Memory. Chicago: University of Chicago Press.

Schwartz, B. (1996). Introduction: expanding the past. Qualitative Sociology, 19(3). Pp. 275282.

Schwartz, B. (1996a). Memory as a cultural system: Abraham Lincoln in World War II. American Sociological Review, 61(5). 908-927.

Schwartz, B. (1996b). Rereading the Gettysburg address: Social change and collective memory. Qualitative Sociology, 19(3). Pp. 395-422.

Schwartz, B. (1991). Social change and collective memory: the democratization of George Washington. American Sociological Review, 56. Pp. 221-236.

Schwartz, B. (1990). The Reconstruction of Abraham Lincoln. In D. Middleton \& D. Edwards (Eds.). Collective Remembering (Pp. 81-107). Beverly Hills: Sage Publications.

Schwartz, B. Zerubavel, Y. Barnett, B. (1986). The recovery of Masada: A study in collective memory. Sociological Quarterly, 27(2). Pp.147-164.

Schwartz, B. (1982). The Social Context of Commemoration: A Study in Collective Memory. Social Forces, 61(2). Pp. 374-402.

Sewell, W. (1990). 'Three Temporalities: Toward a Sociology of the Event'. CSST Working Paper, 58. University of Michigan, Ann Arbor. 
Shils, E. (1981). Tradition. Chicago: University of Chicago Press.

Smelser, N. (2004). September 11, 2001, as cultural trauma. In J.C Alexander (Ed.), Cultural Trauma and Collective Identity (pp. 264-282). Berkely, California: University of California Press.

Sztompka, P. (2000). Cultural Trauma: The Other Face of Social Change. European Journal of Social Theory, 3(4). Doi: 10.1177/136843100003004004.

Talarico, J. Rubin, D. (2003). Confidence, not consistency, characterises flashbulb memories. Psychological Science, 14(5). Pp. 455-461.

Taylor-Gooby, P. (2013). Why do people stigmatise the poor at a time of rapidly increasing inequality, and what can be done about it? The political quarterly 84(1). Pp. 31-42.

Teeger, C. Vinitzky-Seroussi, V. (1997). Controlling for consensus: Commemorating apartheid in South Africa. Symbolic Interaction, 30(1). Pp. 57-58.

Thompson, K. (2013). Cultural trauma and moral panic: 9/11 and the mosque at ground zero affair, in C. Krinsky (Ed.), The Ashgate Research Companion to Moral Panics, (pp. 386400). Ashgate Publishing, Surrey: England.

Touraine, A. (2001). Beyond Neoliberalism. Cambridge: Polity.

Trouillot, M. (1995). Silencing the Past: Power and the Production of History. Boston: Beacon.

Tuchman, G Fortin, N. (1989). Edging Women Out: Victorian Novelists, Publishers, and Social Change. New Haven: Yale University Press.

Turner, V. (1987). The Anthropology of Performance. New York: PAJ Publishers. Retrieved from: http://erikapaterson08.pbworks.com/f/Antrophology+of+performance(2).pdf.

Turner, V. (1982). From Ritual to Theatre: The Human Seriousness of Play. New York: Performing Art Journal Publication.

Turner, V. (1980). Social dramas and stories about them. Critical Inquiry, 7(1). Pp. 141-168. Vinitzky-Seroussi, V. (2002). Commemorating a difficult past: Yitzhak Rabin's memorials. American Sociological Review, 67(1). Pp. 30-51. 
Vinitzky-Seroussi, V. (1998). After Pomp and Circumstance: High School Reunion as an Autobiographical Occasion. Chicago: University of Chicago Press.

Wagner-Pacific, R. (1996). Memories in the making: The shapes of things that went. Qualitative Sociology, 19(3). Pp. 301-321.

Wagner-Pacifici, R. \& Schwartz, B. (1991). The Vietnam veteran's memorial: Commemorating a difficult past. American Journal of Sociology, 97(2). Pp. 376-420.

Weber, C. (2015). Social Memory and War Narratives. Basingstoke, Palgrave Macmillan. Wilkinson, R. (1996) Unhealthy societies: the afflictions of inequality. London: Routledge. The World Top Incomes Database (2013): Retrieved from http://topincomes.gmond.parisschoolofeconomics.eu/\#Home

Ya'ir, G. (2014). Neutrality, objectivity, and dissociation: Cultural trauma and educational messages in German Holocaust memorial sites and documentation centers. Holocaust and Genocide Studies, 28(3). Pp. 482-509.

Zelinsky, W. (1988). Nation into State: The Shifting Symbolic Foundations of American Nationalism. Chapel Hill: University of North Caroline Press.

Zelizer, B. (1995). Reading the past against the grain: The shape of memory studies. Critical Studies in Mass Communication, 12(2). Pp. 214- 239.

Zelizer, B. (1993). Journalists as interpretive communities. Critical Studies in Mass Communication, 10(3). Pp. 219-237.

Zelizer, B. (1992). Covering the Body: The Kennedy Assassination, the Media, and the Shaping of Collective Memory. Chicago: University of Chicago Press.

Zerubavel, E. (2003). Time Maps: Collective Memory and the Social Shape of the Past. University of Chicago Press, Chicago.

Zerubavel, E. (1996). Social memories: Steps to a sociology of the past. Qualitative Sociology, 19(3). Pp. 283-299.

Zerubavel, E. (1981). Hidden Rhythms: Schedules and Calendars in Social Life. Chicago: University of Chicago Press.

Zerubavel, Y. (2002). The 'mythological sabra' and the Jewish past: Trauma, memory and contested identities. Israeli Studies, 7(2). Pp. 115-144. 
Zerubavel, Y. (1995). Recovered Roots. Chicago: University of Chicago Press.

Zerubavel, Y. (1994). Recovered Roots: Collective Memory and the Making of Israeli National Tradition. Chicago: University of Chicago Press. 